\title{
La cuenta de pérdidas y ganancias. El Frente Amplio y la elección de gobiernos departamentales 2010"
}

Antonio $\quad$ Cardarello $^{35}$

\section{Resumen}

En esta presentación nos proponemos analizar los resultados electorales obtenidos por el Frente Amplio (FA) en las elecciones departamentales de 2010. Las interrogantes que se planteaban iban en el sentido de hasta qué punto lograría el FA repetir el éxito de las elecciones de 2005, ¿conseguiría retener los gobiernos departamentales alcanzados entonces? ¿Cómo afrontarían esta elección los partidos tradicionales? ¿Se harían sentir en esta oportunidad los efectos del sistema electoral departamental? ¿O primaría el efecto arrastre de la presidencial como en el ciclo 2004-05?

Este trabajo intenta identificar qué factores ayudan a explicar el declive de la izquierda en el control de Gobiernos Departamentales (GD). En primer lugar parece claro que en mayo de 2010 se apreció una nítida separación entre la elección nacional y la elección departamental a diferencia del ciclo 2004-05 cuando hubo un importante efecto de arrastre de la elección nacional sobre la elección departamental que le permitió al FA incluso ganar varias GD.

El factor relevante en esta instancia fue el estímulo que genera el sistema electoral, en particular el sistema de mayoría simple para la elección del Intendente, que permitió a los partidos tradicionales votar estratégicamente. Otros aspectos del SE como la posibilidad de reelección y la utilización del DVS se vieron relegados frente al efecto de este mecanismo.

Palabras claves: Frente Amplio, gobiernos departamentales, elecciones subnacionales, sistema electoral, nacionalización

\section{Summary}

In this paper we analyze the election results obtained by the Frente Amplio (FA) in 2010 departmental elections. The questions that were posed in the sense of how far achieved the FA repeat the success of the 2005 elections. Get Departmental

${ }^{35}$ Doctor en Ciencia Política. Docente en Régimen de Dedicación Total de la Universidad de la República. Investigador del Instituto de Ciencia Política de la Facultad de Ciencias Sociales. Integrante del Sistema Nacional de Investigadores. 
governments retain achieved then? How would face this choice traditional parties? Does this opportunity would be felt in the electoral system effects department? This time would feel the effects of departmental electoral system?

This paper attempts to identify what factors help explain the decline of the left in the control of departmental governments (GD). Firstly, it seems clear that in May 2010 a clear separation was observed between the national election and departmental election cycle unlike 2004-05 when there was a significant carryover effect of the national election on the election department which allowed the FA reach $\mathrm{GD}$ into seven departments of the country for the first time.

The relevant factor in this instance was the stimulus that generates the electoral system, particularly the simple majority system for the election of Mayor, which allowed traditional parties vote strategically. Other aspects of the SE as the possibility of re-election and DVS utilization were relegated from the effect of this mechanism.

Keywords: Frente Amplio, departmental governments, subnational elections, electoral system, nationalization

\section{Introducción}

Las elecciones departamentales del 9 de mayo 2010 provocaron un reposicionamiento en el plano territorial subnacional para los tres partidos principales del sistema Frente Amplio (FA), Partido Nacional (PN) y Partido Colorado (PC). Era esta la tercera elección departamental separada de las nacionales (luego de la reforma de 1996), donde el FA se presentaba como favorito en muchos departamentos. A esto se sumaba la primera elección de los recientemente creados Municipios.

Este trabajo se ocupa de observar que efectos generó el SE. En particular la idea de la fórmula de mayoría simple (MS) condujo a los escenarios de competencia polarizados entre el FA y alguno de los denominados Partidos Tradicionales (PN y $\mathrm{PC})$.

La hipótesis que planteamos es que el sistema de mayoría simple para la elección de intendente genera un poderoso estímulo que tiende a crear un escenario de competencia entre dos grandes partidos (Duverger, 1957) y que el efecto que este mecanismo provoca es más poderoso respecto a la configuración de los 
escenarios de competencia que los demás componentes del sistema electoral departamental. La mayoría simple para la elección del ejecutivo departamental se configura en un elemento más decisivo que la separación en el tiempo de las elecciones nacionales de las subnacionales, el Doble Voto Simultáneo (DVS) o incluso la reelección inmediata (RI).

El artículo intentará demostrar esto y se estructurará de la siguiente manera: En primer lugar haremos una breve descripción de las reformas introducidas en 1996 y del sistema electoral vigente. A continuación, haremos un repaso de la competencia por los Gobiernos Departamentales (GD) y cuáles eran los objetivos del FA. Luego haremos un repaso de la oferta electoral del FA, en particular de sus candidatos a la reelección. Seguidamente presentaremos los resultados de la elección y cuáles son los escenarios resultantes de los comicios de 2010. Posteriormente nos referiremos a los efectos que el sistema electoral, en particular de la formula de MS puede haber tenido en estos resultados. Finalmente presentaremos unas breves conclusiones.

\section{El marco institucional, la reforma constitucional de 1996.}

Creemos de vital importancia para abordar un análisis de las elecciones departamentales tener presente su marco institucional y en particular hacer referencia a las modificaciones realizadas en 1996 y sus consecuentes efectos en la competencia electoral.

\subsection{Separación de las Elecciones y restricción de la oferta}

La reforma de 1996 abarcó una amplia variedad de tópicos en materia municipal, pero sin duda las transformaciones más trascendentes que consagró a nivel subnacional fueron las referidas al sistema electoral. Las mismas son: 1) Separación en el tiempo de las elecciones municipales respecto a las nacionales; 2) Restricción del DVS limitando a tres el número de candidatos a intendente por lema; 3) La elección de convenciones departamentales.

La separación en el tiempo de las elecciones municipales respecto a las nacionales representó un cambio político fundamental. Esta separación permite una mayor autonomía de la materia departamental y también de la local, a partir de la de creación de los municipios o "autoridades locales" electivas. La separación transforma a esta instancia comicial según Traversa (2001:64) en "[...] una elección independiente, ya no ligada a una elección nacional como antes. Con el viejo sistema era muy probable que la elección del Presidente de la República y las 
propuestas de los diferentes candidatos y partidos en el nivel nacional interfirieran mucho sobre la elección municipal".

Esta disociación temporal ha mostrado servir para realzar la campaña departamental, sobre este punto López (2007) encontró una fuerte influencia del ciclo electoral (que incluye nacionales y departamentales) sobre el comportamiento de los electores. Pero también para reforzar más la figura del Intendente, pues queda más que nunca claro que la elección del ejecutivo comunal es la principal en disputa dejando muy por detrás la importancia que se asigna al legislativo comunal. Permite centrarse más en la persona del candidato, en sus cualidades personales y en su gestión en el caso de que el intendente intente la reelección (Cardarello, 2005 y 2009).

La restricción del DVS en la elección del ejecutivo departamental, ha significado un cambio muy importante e incluso sustantivo que limita algunos casos de oferta excesiva. Anteriormente cada partido podía presentar un número ilimitado de candidatos al ejecutivo departamental ${ }^{36}$. La restricción lleva a que usualmente se presenten 2 y que excepcionalmente puede llegar a ser 3 , siempre que se llegue a acuerdo en el Organismo Deliberativo Departamental (ODD) que posibilite que los dos candidatos que sigan al más votado empaten en el $30 \%$ de los votos del cuerpo.

En este contexto cobra especial relevancia la elección de los ODD, su importancia radica en que son estás quienes elegirán a los futuros candidatos a la Intendencia de cada partido. Esto obliga a los precandidatos a marcar sus votos en las elecciones internas. Para ello deberán realizar una campaña y exhibir no solo sus intenciones de postularse, sino también sus credenciales, negociar apoyos, etc., casi un año antes de los comicios. A este respecto Laurnaga (2001:16) destaca que "[...] si bien la intención del constituyente parece haber estado orientada a postergar la elección departamental para otorgarle autonomía respecto a la nacionales, se produce en realidad un efecto de anticipación de esta competencia a las internas".

\subsection{El sistema electoral departamental. Un régimen sui generis.}

El cargo de Intendente se define por el principio de MS o plurality que consiste en que el partido con más votos se queda con la titularidad del ejecutivo comunal pudiendo presentar más de un candidato $^{37}$ por el sistema de Doble Voto

${ }^{36}$ El PC llegó a presentar 9 candidatos a intendente en Canelones en 1994.

37 La reforma constitucional de 1996 consagró entre otras modificaciones la reducción a 3 candidatos a intendente por partido. La ley estableció que será nominado candidato quién haya sido más votado por los integrantes del ODD. También lo podrá ser quien lo siguiere en 
Simultáneo (DVS) ${ }^{38}$. En el artículo 266 de la Constitución se establece que los Intendentes durarán cinco años en el ejercicio de sus funciones y podrán ser reelectos, por una sola vez, requiriéndose para ser candidatos que renuncien con tres meses de anticipación, por lo menos, a la fecha de las elecciones ${ }^{39}$. Junto con el Intendente se eligen cuatro suplentes quiénes ocuparán el cargo en caso del cese del titular.

En definitiva desde la reforma constitucional de 1996 la elección del intendente se distingue del SE presidencial como bien señala Buquet (2005:19) "[...] en tres aspectos relevantes: i) la fórmula para elegir intendentes es de mayoría relativa, en lugar de la mayoría absoluta que se utiliza para elegir al presidente; ii) los partidos pueden presentar hasta tres candidatos a intendente, a diferencia del candidato único que se exige a los partido en las presidenciales; y iii) está permitida la reelección inmediata de los intendentes por una vez, mientras que los presidentes que aspiran a retornar al cargo deben esperar que se cumpla un período de gobierno".

En cuanto a la elección de la Junta Departamental (JD) el principio de decisión que establece la Constitución es el de representación proporcional integral, sin embargo el partido triunfador tiene asegurada la mayoría absoluta en el caso de que no la hubiere obtenido en la adjudicación normal de bancas ${ }^{40}$. Dentro del lema mayoritario y entre los lemas restantes el sistema es proporcional ${ }^{41}$.

número de votos siempre que superare el $30 \%$ de los sufragios emitidos. Cada convencional o integrante del ODD votará por un sólo candidato. La Corte Electoral autorizó a los partidos a llevar hasta 3 candidatos. Si el segundo lugar en la Convención resultara en un empate en $30 \%$, dicho órgano podrá nombrar a ambos.

${ }^{38}$ El DVS permite la presentación dentro de un partido o lema de diferentes candidatos para un mismo cargo. Esto significa que el elector vota a dos niveles, primero por un partido y luego al interior del mismo por un candidato o lista de candidatos. Es un mecanismo de los que se denomina de voto preferencial intra partidario.

${ }^{39}$ En la legislatura (2000-05) se aprobó un proyecto de ley, presentado por parte de los senadores Jorge Larrañaga (PN) y Rubén Correa Freitas (PC), que determinaba el periodo que deben computar los suplentes de intendentes para poder ser reelectos. Este expresa en su artículo único que quienes habiendo sido electos como suplentes del cargo de Intendente hayan desempeñado el cargo de Intendente por más de treinta meses, en forma continua o alternada, se considerará que han cumplido un período completo a los efectos de la reelección conforme a lo establecido por el artículo 266 de la Constitución de la República. Ley No 17.797.

${ }^{40}$ El sistema ha sido definido como mayoritario y subsidiariamente proporcional por Bottinelli (1991) y de mayoría automática por Moraes (1997).

${ }^{41} \mathrm{Si}$ el partido del Intendente sólo hubiese obtenido la mayoría relativa de sufragios se le adjudicará la mayoría (16) de los 31 cargos de la Junta Departamental, los que serán 
En el periodo que va entre 1934-1994 las elecciones nacionales (Presidente, Vicepresidente y las cámaras legislativas) y departamentales (Intendente y Juntas Departamentales) eran simultáneas -se realizaban el mismo día- y estaban vinculadas. Esto porque si bien existía una hoja de votación para los cargos nacionales y otra hoja para los cargos locales, no era posible votar por lemas diferentes en los distintos ámbitos; si esto acontecía el voto se anulaba ${ }^{42}$. Esta simultaneidad y vinculación de la elección provocaba un efecto de "arrastre" de la elección nacional sobre la departamental. La única chance que tenía el elector para no verse obligado a sufragar por el mismo lema en ambos ámbitos era votar en blanco en uno de los niveles, por un lema en la elección nacional y en blanco en la municipal o por un lema en lo municipal y en blanco en lo nacional.

La consagración de la separación de las elecciones nacionales de las departamentales y departamentales no ha generado unanimidades y ha recibido críticas de incluso algunos de sus propios impulsores. Por un lado se critica porque alarga innecesariamente un ciclo electoral que se vuelve por demás extenso, la solución propuesta sería a juntar las instancias habilitando el voto cruzado (por un partido a nivel nacional y por otro diferente a nivel subnacional). Por otro lado se señala la excesiva proximidad entre ambos actos electorales, inclinándose por un lapso no menor a dos años entre una instancia y la otra. Aquí la solución sería la contraria proponiéndose que se realizará a medio periodo.

\section{Consolidación y desafíos del FA. La nacionalización y la competencia por los GD}

El FA nació en 1971 (dos años antes del golpe de estado de junio de 1973) como una coalición de grupos y partidos de izquierda ${ }^{43}$. Desde sus inicios el FA se

distribuidos proporcionalmente entre todas sus listas. Los restantes 15 bancas son distribuidas por el sistema de RP.

42 La excepción la constituyó el período en que rigió la Constitución de 1942, elecciones de 1946 y 1950 , en que el nivel municipal estaba desvinculado del nacional. Las elecciones eran simultáneas en el tiempo, pero como dos instancias separadas. Existían dos hojas y el elector podía combinarlas como quisiera: podía votar por un lema en lo nacional y por otro en lo departamental usando el denominado "voto cruzado". Incluso en esa oportunidad la Corte habilitó lemas departamentales, agrupaciones que contaban con completa libertad en lo que se refiere a la afiliación política de sus integrantes.

43 Los grupos políticos que conformaron dicha alianza: Partido Socialista, Partido Demócrata Cristiano, Partido Comunista, sectores escindidos de los partidos tradicionales (la 
concentró electoralmente en la capital del país, Montevideo, donde fue la segunda fuerza en 1971 y 1984 hasta que obtuvo el gobierno departamental por primera vez en 1989. En cuanto al interior, el crecimiento se dio a un ritmo más lento, siendo en el sudeste y en el litoral (coincidentemente con los indicadores de modernización más favorables) donde el FA aceleró su crecimiento luego de 1994. Durante muchos años, superar el clivaje Montevideo-Interior se consideró una de las "asignaturas pendientes" de la izquierda. En 1971 los votos cosechados fuera de Montevideo eran un $30 \%$ del total, y en 1989 fueron un 25\%, mientras que en octubre de 1999 ya habían alcanzado casi un $44 \%$, lo cual supuso un cambio sensible y el pasaje de un partido basado principalmente en Montevideo a otro de verdadero alcance nacional, legitimado en todo el país.

\section{Gráfico 1 Evolución del FA Montevideo-Interior (1971-2009)}

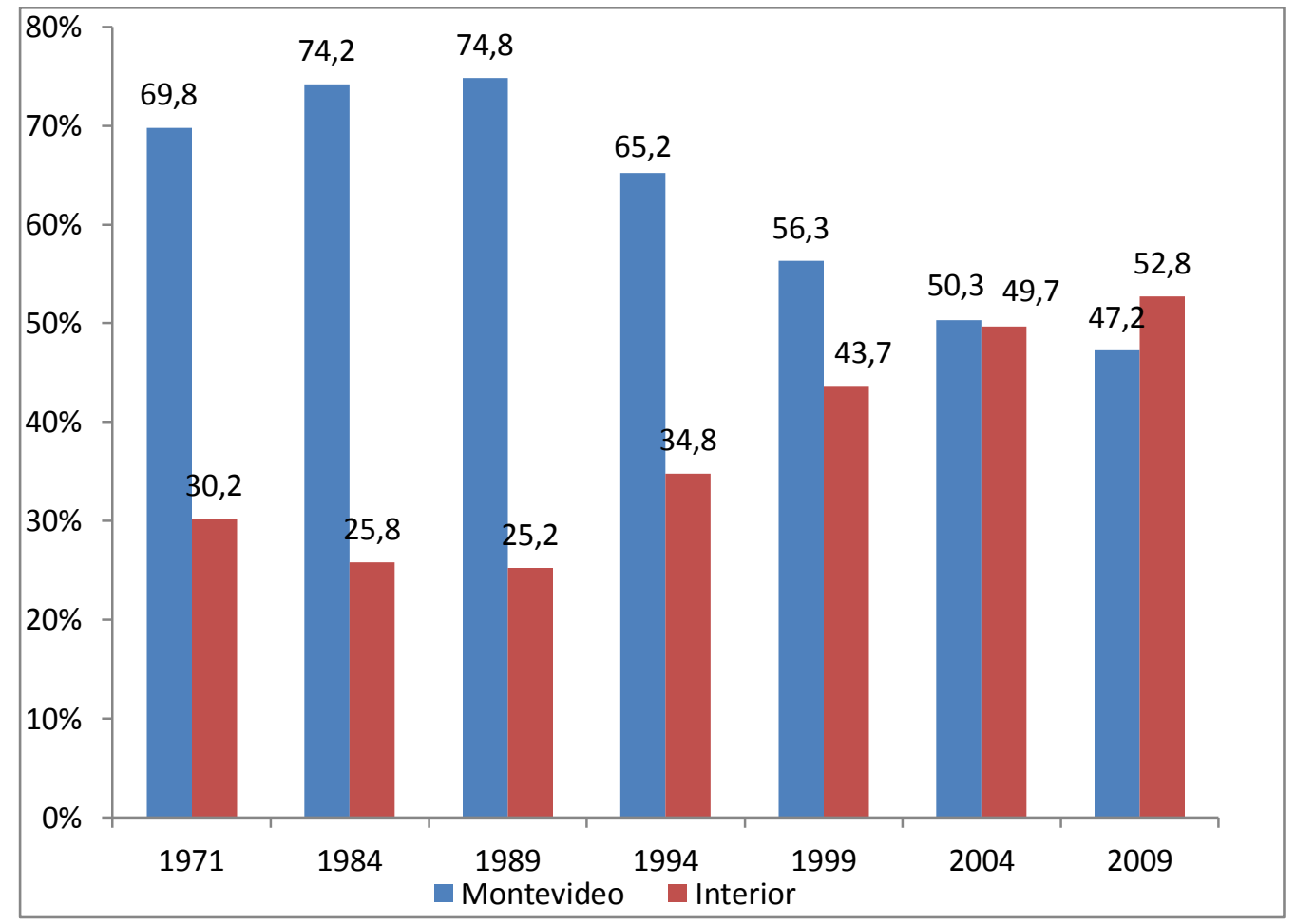

lista 99 y Pregón del P. Colorado, y la lista 58 y el Movimiento Blanco Popular y Progresista del P. Nacional) el Movimiento Socialista y pequeños grupos de izquierda. A poco de su fundación se le agregaron la Unión Popular de Enrique Erro y el flamante Movimiento 26 de Marzo, expresión legal conectada con el MLN-Tupamaros. Sus bases sociales de apoyo incluyeron a los movimientos sociales organizados, en especial el movimiento sindical y estudiantil, así como parte importante de la intelectualidad y del mundo universitario. 
Fuente: Elaboración propia sobre datos de la Corte Electoral y del Banco de Datos de la $\mathrm{FCS}^{44}$.

\section{Gráfico 2 Evolución electoral Montevideo-Interior (1971-2009)}

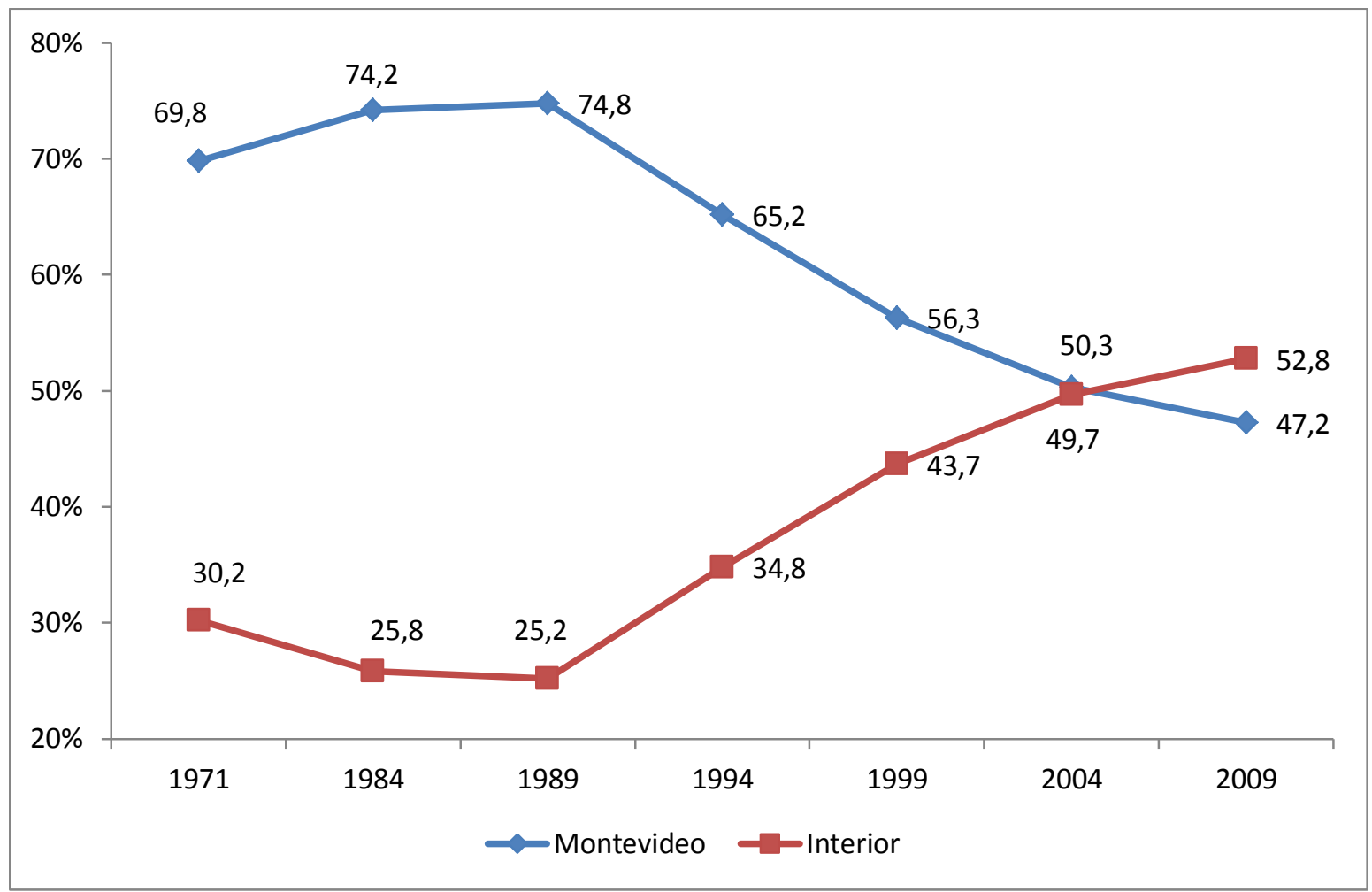

Fuente: Elaboración propia sobre datos de la Corte Electoral y del Banco de Datos de la $\mathrm{FCS}^{45}$.

Rumbo a las elecciones de 2010, el FA tenía como gran objetivo retener los ocho GD obtenidos cinco años antes e incluso sumar alguno más. Las elecciones departamentales eran también una oportunidad para confirmar la creciente nacionalización (Jones y Mainwaring, 2003) de la izquierda ${ }^{46}$.

\subsection{La nacionalización del FA. Elevada y en alza}

${ }^{44}$ Banco de Datos, Unidad de Política y Relaciones Internacionales de la Facultad de Ciencias Sociales, Universidad de la República.

${ }^{45}$ Banco de Datos, Unidad de Política y Relaciones Internacionales de la Facultad de Ciencias Sociales, Universidad de la República.

${ }^{46}$ Sobre este particular ver Cardarello y Guerrini (2004). 
El referido estudio de Jones y Mainwaring (2003) resulta de particular interés tanto por la definición de nacionalización del sistema de partidos como por su operacionalización. Los autores definen nacionalización, en base a Schattschneider (1960) y Sundquist (1973), como "...el grado en que las unidades subnacionales se asemejan a los patrones de votación nacionales" (2003:67). Tenemos entonces dos indicadores: el índice de nacionalización de partidos (INP) ${ }^{47}$ y el índice de nacionalización del sistema de partidos (INSP). El primero permite ver la evolución de un partido en el tiempo y compararlo con partidos dentro y fuera del sistema; el segundo resulta útil para comparar sistemas ${ }^{48}$. En el caso uruguayo las explicaciones que los autores manejan para el período que analizan (1984-1999), se verifican.

En primer término existiría un alto nivel de nacionalización asociado a sistemas unitarios; lo que se confirma en el caso uruguayo, observándose un promedio de 0,88 entre 1984 y 2009, que resulta en un alto grado de nacionalización. Además, Uruguay se ubica entre los sistemas de partidos más nacionalizados de América ${ }^{49}$ y segundo en estabilidad de la nacionalización.

\footnotetext{
${ }^{47}$ Se utiliza el índice de Gini invertido (1-Gini) para que un valor alto indique alta nacionalización.

${ }^{48}$ Para ver la operacionalización de estos indicadores, ver Jones y Mainwaring (2003:70, 9698)

49 Jones y Mainwaring consideran 17 países: 15 latinoamericanos, Estados Unidos y Canadá, desde 1979.
} 


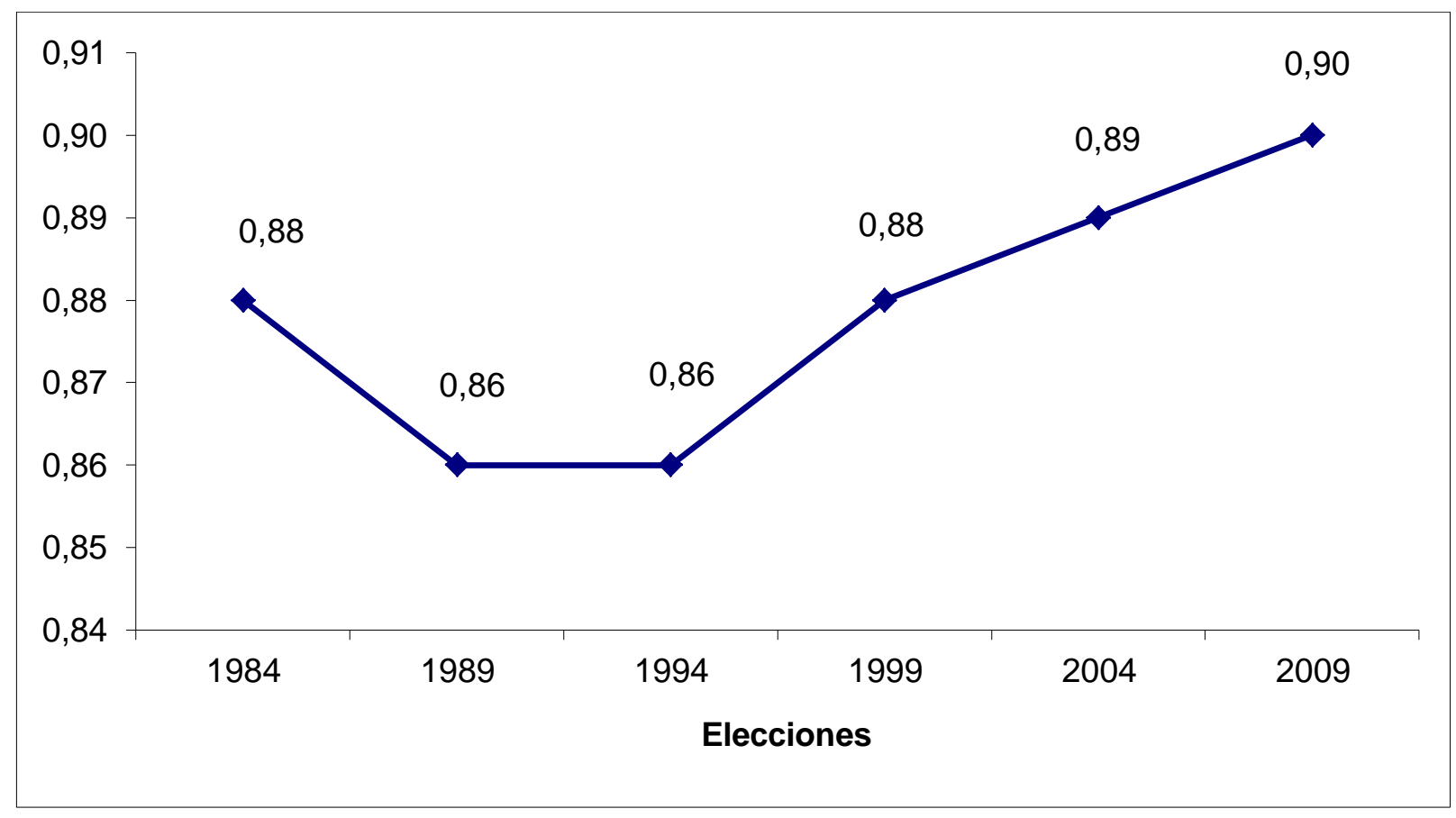

Fuente: Elaboración propia sobre datos de la Corte Electoral y del Banco de Datos de la FCS ${ }^{50}$.

En segundo lugar se verifica la relación positiva entre baja fragmentación y alta nacionalización. Tercero, también se verifica la relación inversa entre volatilidad -que tuvo su mayor expresión en 2004- y nacionalización. Por último, la relación entre crecimiento electoral y nacionalización se confirmaría visiblemente en el FA por su crecimiento sostenido; el PN descendió hacia 1999 retomando en 2004 su alto nivel de INP para luego caer levemente en 2009, en tanto el PC estuvo entre los once más nacionalizados hasta 1999, bajando en la escala por la votación 2004 y recuperándose parcialmente en 2009.

${ }^{50}$ Banco de Datos, Unidad de Política y Relaciones Internacionales de la Facultad de Ciencias Sociales, Universidad de la República. 
Gráfico 4 Evolución INP Partidos más relevantes (1984-2009)

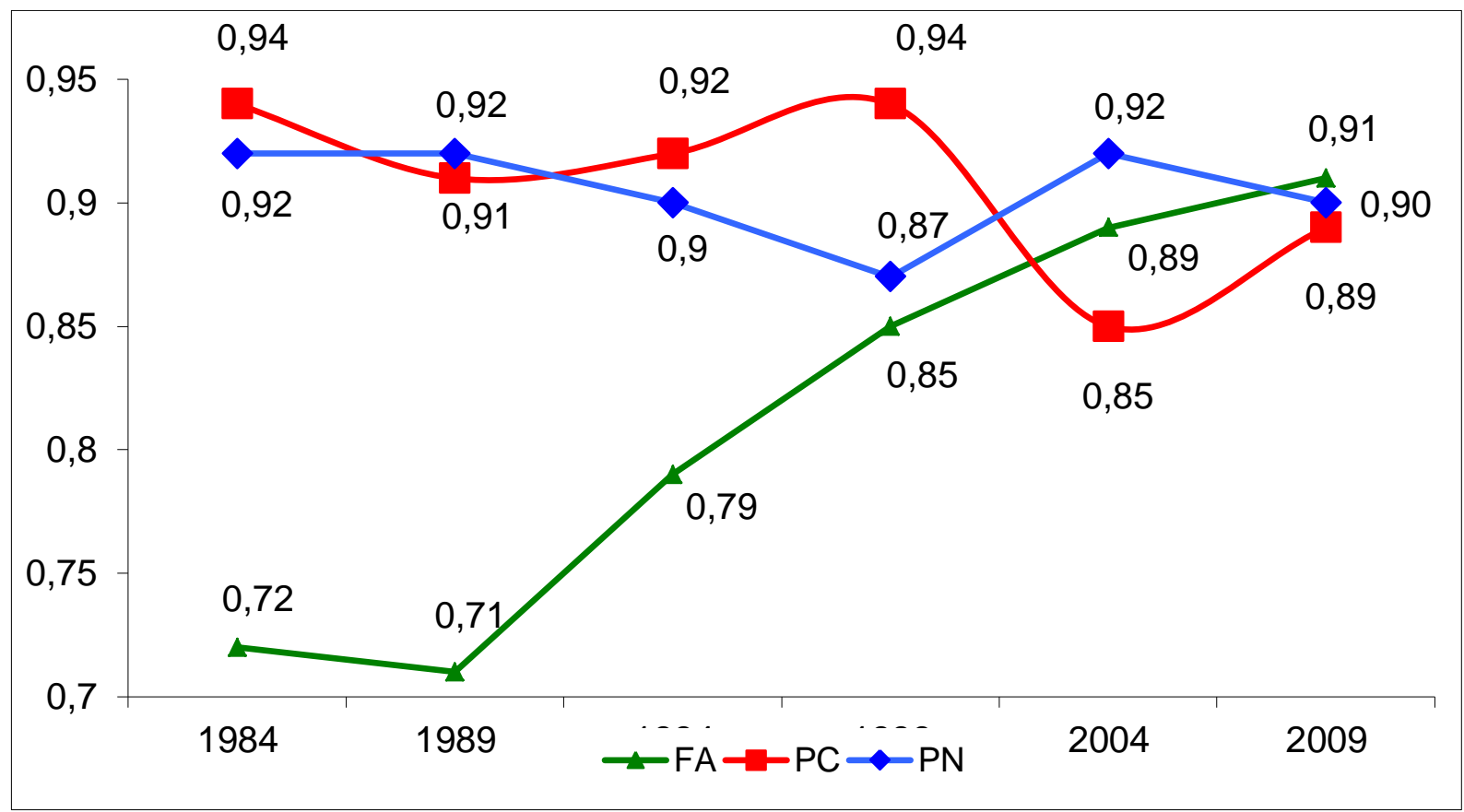

Fuente: Elaboración propia sobre datos de la Corte Electoral y del Banco de Datos de la FCS.

En el último ciclo electoral se observa claramente que el FA es el partido más nacionalizado del sistema tanto en las elecciones nacionales como en las departamentales.

Tabla 2 Nacionalización de los partidos y del sistema de partidos (2009-10)

\begin{tabular}{|c|c|c|c|c|c|c|c|}
\hline \multicolumn{4}{|c|}{ INSP Nacionales 2009} & \multicolumn{4}{|c|}{ INSP Departamentales 2010} \\
\hline Partido & INP & $\%$ Votos & & Partido & INP & $\%$ Votos & \\
\hline$\overline{F A}$ & 0,91 & 0,49 & 0,45 & $\overline{F A}$ & 0,84 & 0,47 & 0,39 \\
\hline PC & 0,89 & 0,18 & 0,16 & PC & 0,62 & 0,17 & 0,11 \\
\hline PN & 0,90 & 0,30 & 0,27 & PN & 0,81 & 0,34 & 0,28 \\
\hline
\end{tabular}




\begin{tabular}{|l|l|l|l|} 
PI & 0,79 & 0,03 & 0,02 \\
PI & 0,74 & 0,01 & 0,01 \\
\hline INSP & $\mathbf{0 , 9 0}$ \\
\hline
\end{tabular}

\begin{tabular}{|l|l|l|l|} 
PI & 0,49 & 0,01 & 0,00 \\
AP & 0,47 & 0,01 & 0,00 \\
\hline INSP & & & $\mathbf{0 , 7 9}$ \\
\hline
\end{tabular}

Fuente: Elaboración propia sobre datos de la Corte Electoral y del Banco de Datos de la FCS.

Resulta interesante observar que pasa una vez que las elecciones departamentales se separan de las nacionales. El siguiente gráfico nos permite observar que en los tres ciclos ocurridos desde entonces, si bien ambos índices van en alza y la diferencia es mínima, consistentemente el INSP nacional es un poco más alto que el departamental.

Respecto a qué factores pueden estar operando en ello, podemos mencionar entre otros al hecho de que el sistema electoral de mayoría simple crea escenarios de competencia bipolar y desestimula la presencia de un tercer partido. Esto se refleja en que el partido que ha quedado en tercer lugar en los comicios para autoridades locales, muestra un índice de nacionalización bastante más bajo que los otros dos. Esto se aprecia en forma clara en el caso del PC en las elecciones de 2005 y 2010. En este último el PC (ver tabla 6) concentró su votos en los departamentos en que compitió por el GD, Rivera y Salto, en tanto perdió apoyos en departamentos como Florida, donde la disputa por el GD se desarrollaba entre el FA y el PN. 
Gráfico 5 INSP en elecciones nacionales y departamentales (1999-2010)

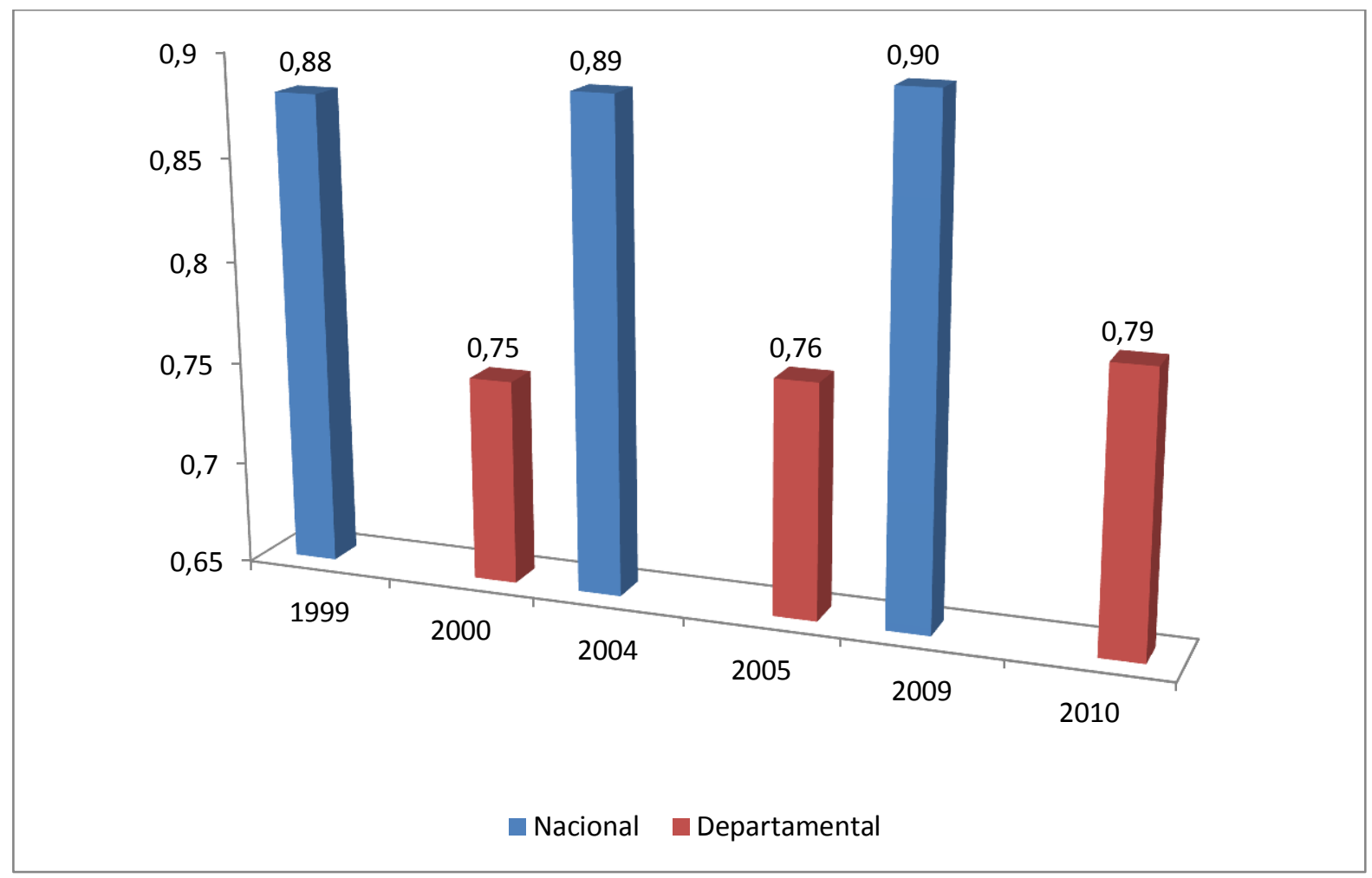

Fuente: Elaboración propia sobre datos de la Corte Electoral y del Banco de Datos de la FCS.

En el siguiente gráfico se observa como el FA pasa de ser el partido con menor INP en las elecciones de 2000, pasa a encabezar el ranking a partir de 2005, mientras que el PC se desploma estrepitosamente en 2005, si bien exhibe una modesta mejoría en 2010, y el PN se mantiene estable. 


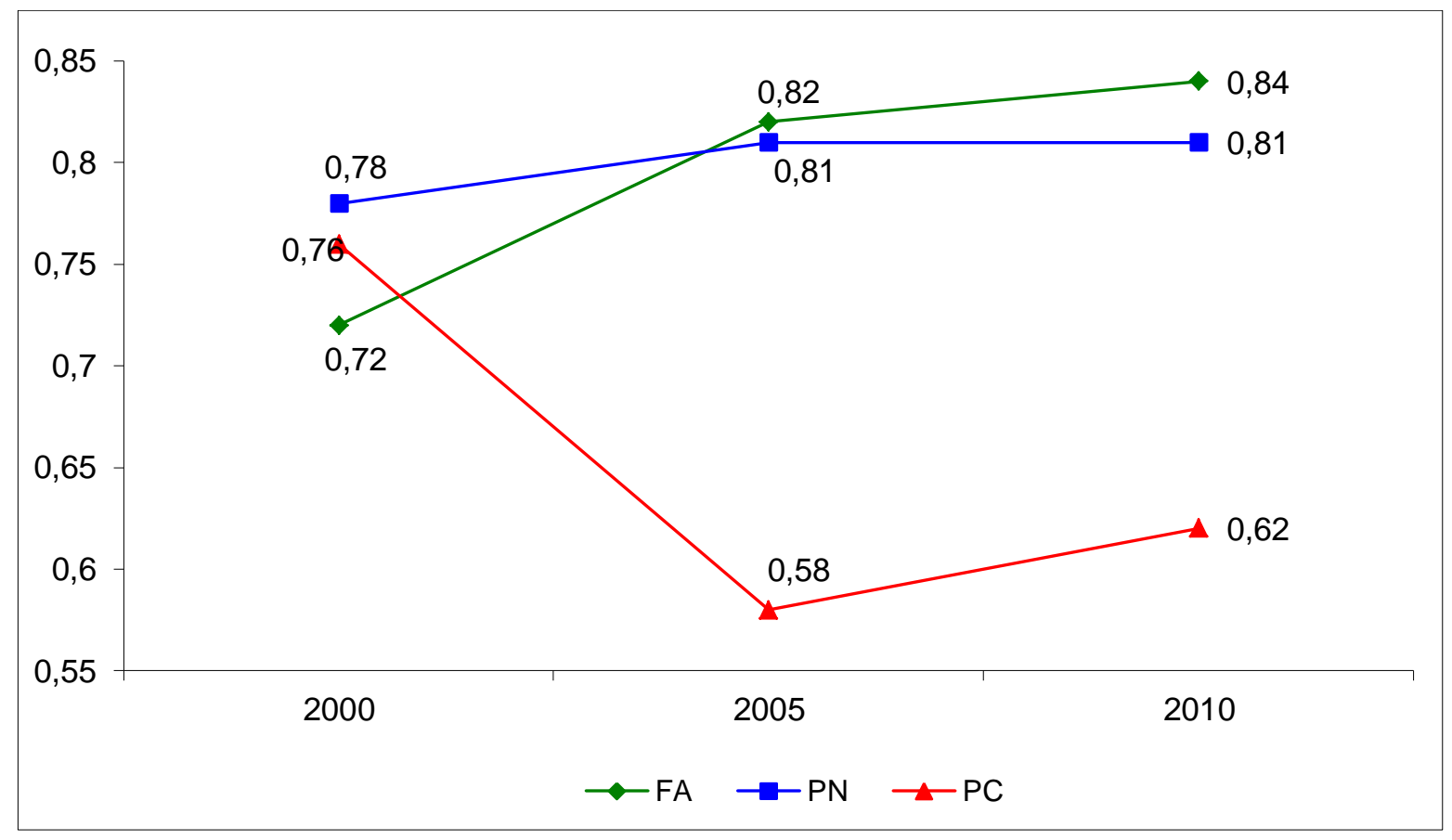

Fuente: Elaboración propia sobre datos de la Corte Electoral y del Banco de Datos de la FCS.

\subsection{Los escenarios y la oferta de candidaturas}

Como vimos el DVS permite presentar hasta tres candidatos por partido. Este mecanismo permite que se desarrolle una competencia intrapartidaria simultánea a la interpartidaria. Esto provoca por un lado que el partido pueda presentar una oferta variada que posibilita acrecentar su potencial, pero por otro lado la competencia interna tiene sus riesgos, de modo que si un partido presenta una interna demasiado ríspida, es probable que pierda la elección ${ }^{51}$.

El proceder del FA respecto a la utilización del DVS fue diferente según el caso. De hecho bloqueó la múltiple candidatura en Montevideo, Canelones y Rocha

${ }^{51}$ En 2005 la interna del PN en Treinta y Tres y Florida fue un factor de una importancia considerable que jugó contra la suerte de intendentes nacionalistas que procuraban la reelección. 
y la permitió en los restantes Departamentos. En algunos casos quedó a criterio de los candidatos reelegibles (incumbents) y su relación con sectores locales del partido. De este modo se abrió la competencia en Paysandú, Maldonado, Treinta y Tres y Salto. En el caso de Paysandú entre el incumbent Julio Pintos del Partido Socialista (PS) y Salomé Wolman, perteneciente al Espacio 609 (E609), se reprodujo la disputa entre los dos sectores con mayor vocación por controlar GD.

Al igual que en el PC y el PN, la oferta de candidaturas en el FA replicó en todos los Departamentos la estructura de los sectores nacionales ${ }^{52}$. A la ya mencionada entre el E609 y el PS se sumaron algunas excepciones como la de la Liga Federal Frenteamplista (LFF) que presentó en Maldonado y Florida con un carácter netamente regional. El FA presentó un total de 41 candidatos en todo el país que se distribuyeron de la siguiente forma.

Tabla 3 Candidatos a Intendentes del FA por fracción

\begin{tabular}{|l|l|l|l|l|l|l|}
\hline Departamento & E609 & PS & AP & PCU & Otros & Total \\
\hline Montevideo & - & - & - & 1 & - & 1 \\
\hline Canelones & - & - & - & - & 1 & 1 \\
\hline Maldonado & 1 & - & 1 & - & 1 & 3 \\
\hline Rocha & - & 1 & - & - & - & 1 \\
\hline Treinta y Tres & 1 & 1 & - & - & - & 2 \\
\hline Cerro Largo & - & 1 & 1 & - & - & 2 \\
\hline Rivera & 1 & 1 & - & - & 1 & 3 \\
\hline Artigas & 1 & - & 1 & - & - & 2 \\
\hline Salto & 1 & - & - & 1 & 1 & 3 \\
\hline Paysandú & 1 & 1 & - & - & - & 2 \\
\hline Río Negro & 1 & - & - & - & 2 & 3 \\
\hline Soriano & 1 & 1 & - & - & 1 & 3 \\
\hline
\end{tabular}

52 Sobre la competencia intrapartidaria y la coordinación de sectores nacionales y departamentales ver Vairo (2008) 


\begin{tabular}{|l|l|l|l|l|l|l|}
\hline Colonia & 1 & 1 & - & - & 1 & 3 \\
\hline San José & 1 & 1 & - & - & - & 2 \\
\hline Flores & 1 & - & - & - & 1 & 2 \\
\hline Florida & 1 & - & - & - & 1 & 2 \\
\hline Durazno & 1 & 1 & - & - & - & 2 \\
\hline Lavalleja & 1 & - & - & - & - & 1 \\
\hline Tacuarembó & 1 & 2 & - & - & - & 3 \\
\hline Total & 15 & 11 & 3 & 2 & 10 & 41 \\
\hline
\end{tabular}

Fuente: Elaboración propia sobre datos de la Corte Electoral y del Banco de Datos de la FCS ${ }^{53}$.

Del total de candidatos del FA un total de 26 pertenecían a los 2 sectores mencionados, 15 correspondían al E609 -MPP más aliados-, 11 al PS, 3 de Alianza Progresista (AP), 2 del Partido Comunista (PCU) y los restantes 10 de otros sectores

\section{Sorpresa y decepción: Los elecciones del $\mathbf{9}$ de mayo de $\mathbf{2 0 1 0}$}

Los comicios de 2010 muestran que el FA sufrió un retroceso ya que perdió los GD de Treinta y Tres, Salto, Paysandú y Florida al tiempo que conquistó Artigas y conservó Montevideo, Canelones, Maldonado y Rocha, con un saldo negativo en materia de GD.

${ }^{53}$ Banco de Datos, Unidad de Política y Relaciones Internacionales de la Facultad de Ciencias Sociales, Universidad de la República. 
Tabla 4 Votos válidos (\%) por partido en las elecciones departamentales 2010

\begin{tabular}{|l|l|l|l|l|l|}
\hline Departamento & FA & PN & PC & PI & AP \\
\hline Montevideo & $\mathbf{5 3 , 3}$ & 22,9 & 21,0 & 1,5 & 1,3 \\
\hline Canelones & $\mathbf{6 0 , 6}$ & 26,3 & 11,0 & 1,3 & 0,8 \\
\hline Maldonado & $\mathbf{5 2 , 0}$ & 33,1 & 13,7 & 1,0 & 0,2 \\
\hline Rocha & $\mathbf{5 7 , 5}$ & 33,0 & 8,5 & 0,5 & 0,6 \\
\hline Treinta y Tres & 42,3 & $\mathbf{5 1 , 6}$ & 5,5 & 0,3 & 0,3 \\
\hline Cerro Largo & 38,3 & $\mathbf{5 3 , 3}$ & 8,2 & 0,0 & 0,1 \\
\hline Rivera & 22,5 & 26,1 & $\mathbf{5 1 , 1}$ & 0,3 & 0,0 \\
\hline Artigas & $\mathbf{4 7 , 4}$ & 42,2 & 10,0 & 0,1 & 0,2 \\
\hline Salto & 42,2 & 13,0 & $\mathbf{4 3 , 9}$ & 0,7 & 0,1 \\
\hline Paysandú & 44,8 & $\mathbf{4 6 , 6}$ & 8,1 & 0,0 & 0,6 \\
\hline Río Negro & 38,8 & $\mathbf{4 4 , 8}$ & 16,4 & 0,0 & 0,0 \\
\hline Soriano & 34,4 & $\mathbf{5 8 , 1}$ & 6,6 & 0,6 & 0,3 \\
\hline Colonia & 33,2 & $\mathbf{5 5 , 7}$ & 10,9 & 0,0 & 0,2 \\
\hline San José & 34,7 & $\mathbf{5 9 , 9}$ & 4,2 & 0,7 & 0,5 \\
\hline Flores & 25,0 & $\mathbf{6 3 , 4}$ & 10,9 & 0,7 & 0,0 \\
\hline Florida & 44,1 & $\mathbf{4 4 , 7}$ & 10,9 & 0,0 & 0,3 \\
\hline Durazno & 27,8 & $\mathbf{6 4 , 3}$ & 6,8 & 0,8 & 0,4 \\
\hline Lavalleja & 34,0 & $\mathbf{5 6 , 1}$ & 9,1 & 0,7 & 0,1 \\
\hline Tacuarembó & 24,3 & $\mathbf{7 0 , 3}$ & 5,4 & 0,0 & 0,0 \\
\hline TOTAL & 47,2 & 34,4 & 16,7 & 0,9 & 0,7 \\
\hline
\end{tabular}

Fuente: Elaboración propia sobre datos de la Corte Electoral y del Banco de Datos de la FCS

El FA pasó de controlar 8 GD que representaban el 73,3\% de población y $80 \%$ PIB del país, a 5 que representan $64,6 \%$ de la población Igualmente permanecen bajo su gobierno casi dos tercios de la población, esto hace que la reducción de su presencia en el escenario departamental sea menos traumática al menos en principio. Entre estos retuvo los 3 departamentos que conforman la denominada zona metropolitana y que son además los que concentran mayor población (Montevideo, Canelones y Maldonado). A los mencionados se le suma el departamento de Rocha ubicado al este. En definitiva, con la excepción de Artigas (situado en el extremo norte del país) la presencia del FA se concentra en el sur del territorio nacional. 
Tabla 5 Intendentes electos en 2010

\begin{tabular}{|l|l|l|l|l|}
\hline Departamento & Intendente & Partido & Fracción & Cargo anterior \\
\hline Montevideo & Ana Olivera & FA & PCU & $\begin{array}{l}\text { Subsecretaria } \\
\text { MIDES }\end{array}$ \\
\hline Canelones & Marcos Carámbula & FA & Ind. & Incumbente \\
\hline Maldonado & Oscar de los Santos & FA & AP & Incumbente \\
\hline Rocha & Artigas Barrios & FA & PS & Incumbente \\
\hline Treinta y Tres & Dardo Sánchez & PN & UNA & Diputado \\
\hline Cerro Largo & Sergio Botana & PN & AN & Diputado \\
\hline Rivera & Marne Osorio & PC & Proba & Diputado \\
\hline Artigas & Patricia Ayala & FA & MPP & Diputada \\
\hline Salto & Germán Coutinho & PC & VU & Senador ${ }^{54}$ \\
\hline Paysandú & Bertil Bentos & PN & AN & Diputado \\
\hline Rio Negro & Omar Lafluf & PN & AN & Incumbente \\
\hline Soriano & Guillermo Besozzi & PN & AN & Incumbente \\
\hline Colonia & Walter Zimmer & PN & AN & Incumbente \\
\hline San José & José Luis Falero & PN & UNA & Secretario Municipal \\
\hline Flores & Armando & PN & UNA & Incumbente \\
\hline Florida & Carlos Enciso & PN & UNA & Diputado \\
\hline Durazno & Aenjamín Irazábal & PN & UNA & Suplente Intendente \\
\hline Lavalleja & Wilson Esquerra & PN & AN & Incumbente \\
\hline Tacuarembó & PN & AN & Diputada \\
\hline
\end{tabular}

Fuente: Elaboración propia sobre datos de la Corte Electoral y del Banco de Datos de la FCS

${ }^{54}$ En octubre de 2009 también resultó electo diputado, pero optó por la banca en la cámara alta. 
Los resultados a la interna del FA arrojaron que los 5 Intendentes pertenecen a distintos sectores: Montevideo (PCU), Canelones (Ind.), Maldonado (AP), Rocha (PS) y Artigas (E609). Una referencia especial merece el hecho de que por primera vez fueron electas mujeres como intendentes ${ }^{55}$, sin duda es una novedad importante de estas elecciones que vale destacar. Por primera vez mujer obtiene un cargo ejecutivo en Uruguay ${ }^{56}$.

Haciendo un análisis sobre la evolución de los resultados por partido a lo largo del período post-dictadura, podríamos preguntarnos ¿cambia de manera significativa la relación entre el voto nacional y departamental cuando las elecciones se separan en el tiempo y se desvincula el voto en unas y otras? Parece claro que se produjo un corte a partir de la separación los comicios nacionales y departamentales. Entre 1984 y 1994 los partidos tradicionales o fundacionales (PPTT) controlaban 18 de los 19 GD. A partir de la separación se produce justamente la caída del PC y el crecimiento sostenido del FA. Claramente en el periodo 1984-94 el PN es el partido con más GD seguido por el PC, mientras que en el periodo 2000-10 el PN aumenta su ventaja, incluso la elección de 2000 primera con las nuevas reglas permitió la recuperación del PN pese a la debacle de octubre de 1999, mejorando incluso su desempeño de 1994. La novedad post reforma es que el FA desplaza al PC como segunda fuerza en cuanto a GD conquistados a partir de 2005.

\footnotetext{
${ }^{55}$ Ana Olivera (FA) en Montevideo, Patricia Ayala (FA) en Artigas y Adriana Peña (PN) en Lavalleja

56 La excepción en este sentido es la elección de Alba Roballo en el Concejo Municipal de Montevideo por el periodo 1955-59, pero se trata de un organismo colegiado en el que Roballo ocupaba el segundo lugar en la lista y por tanto no era un cargo unipersonal. Para más información sobre las candidaturas de mujeres a los ejecutivos departamentales ver Johnson (2005) y Pérez (2005).
} 
Gráfico 7 Gobiernos Departamentales por Partido por elección (1984-2010)

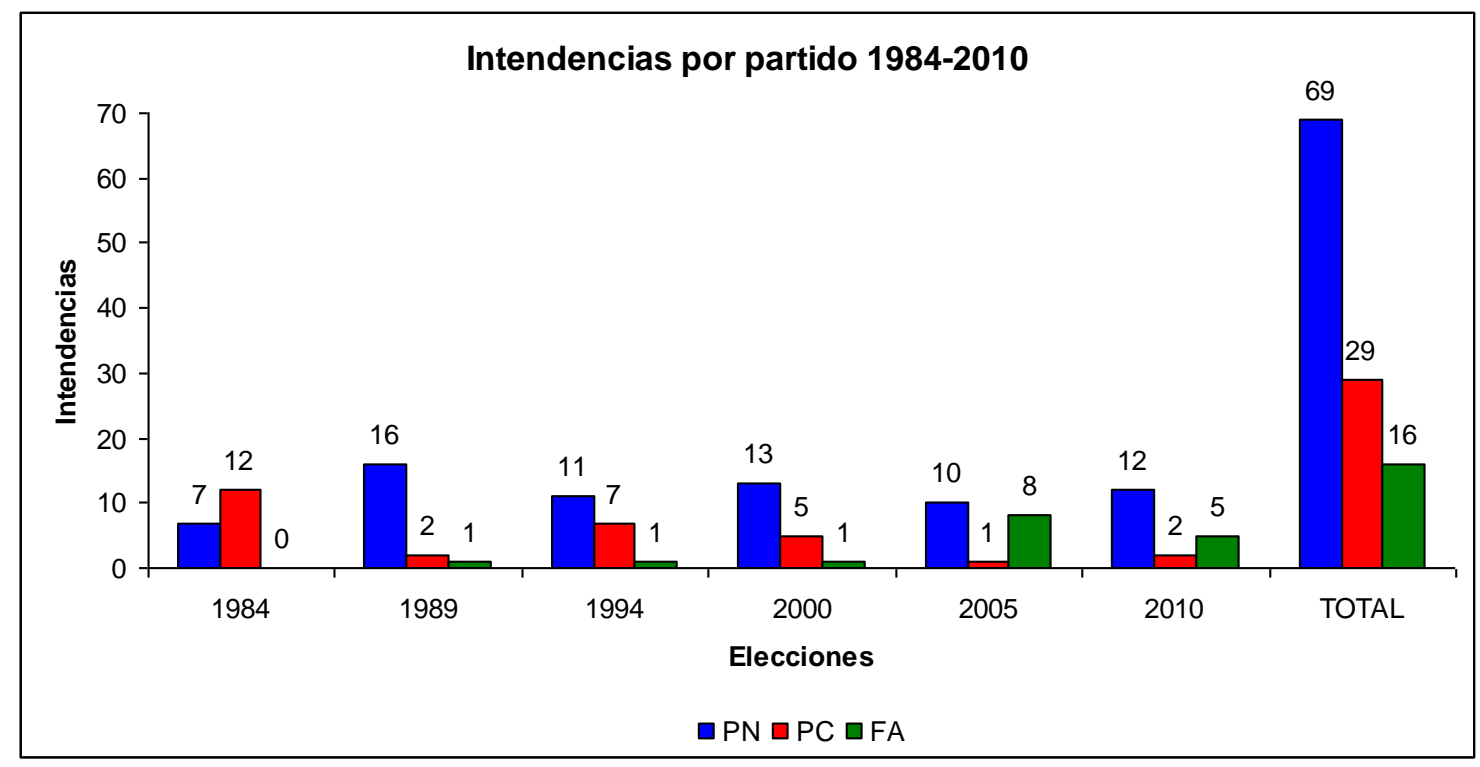

Fuente: Elaboración propia sobre datos de la Corte Electoral y del Banco de Datos de la FCS

\subsection{Ganancias y pérdidas respecto a 2005}

El FA obtuvo un importante incremento en Artigas (31\%), que le permitió ganar el GD y también registró un aumento en Rocha (11\%) y Maldonado (7\%) donde retuvo el GD. Pero paradójicamente su votación también creció en 2 departamentos donde no obstante perdió la elección -Salto (5\%) y Florida (3\%)-.

Tabla 6 Comparación resultados FA en elecciones departamentales 2005 y 2010

\begin{tabular}{|l|l|l|l|l|}
\hline Departamento & $\mathbf{2 0 0 5}$ & $\mathbf{2 0 1 0}$ & Diferencia (\%) & Crecimiento \\
\hline Montevideo & $\mathbf{6 0 , 9}$ & $\mathbf{5 3 , 3}$ & $-7,6$ & $-12 \%$ \\
\hline Canelones & $\mathbf{6 4 , 5}$ & $\mathbf{6 0 , 6}$ & $-3,9$ & $-6 \%$ \\
\hline
\end{tabular}




\begin{tabular}{|l|l|l|l|l|}
\hline Maldonado & $\mathbf{4 8 , 7}$ & $\mathbf{5 2 , 0}$ & 3,3 & $7 \%$ \\
\hline Rocha & $\mathbf{5 1 , 7}$ & $\mathbf{5 7 , 5}$ & 5,8 & $11 \%$ \\
\hline Treinta y Tres & $\mathbf{4 6 , 0}$ & 42,3 & $-3,7$ & $-8 \%$ \\
\hline Cerro Largo & 34,7 & 38,3 & 3,6 & $10 \%$ \\
\hline Rivera & 21,3 & 22,5 & 1,2 & $6 \%$ \\
\hline Artigas & 36,2 & $\mathbf{4 7 , 4}$ & 11,2 & $31 \%$ \\
\hline Salto & $\mathbf{4 0 , 2}$ & 42,2 & 2,0 & $5 \%$ \\
\hline Paysandú & $\mathbf{4 8 , 7}$ & 44,8 & $-3,9$ & $-8 \%$ \\
\hline Rio Negro & 41,5 & 38,8 & $-2,7$ & $-7 \%$ \\
\hline Soriano & 35,6 & 34,4 & $-1,2$ & $-3 \%$ \\
\hline Colonia & 34,8 & 33,2 & $-1,6$ & $-5 \%$ \\
\hline San José & 34,8 & 34,7 & $-0,1$ & $0 \%$ \\
\hline Flores & 18,2 & 25,0 & 6,8 & $37 \%$ \\
\hline Florida & $\mathbf{4 2 , 9}$ & 44,1 & 1,2 & $3 \%$ \\
\hline Durazno & 31,7 & 27,8 & $-3,9$ & $-12 \%$ \\
\hline Lavalleja & 21,0 & 34,0 & 13,0 & $62 \%$ \\
\hline Tacuarembó & 22,2 & 24,3 & 2,1 & $9 \%$ \\
\hline Fuente: Ela & & & & \\
\hline
\end{tabular}

Fuente: Elaboración propia sobre datos de la Corte Electoral y del Banco de Datos de la FCS

Su votación menguó no solo en aquellos departamentos donde perdió el GD, un $-8 \%$ en Treinta y Tres y Paysandú, sino que también vio disminuir su electorado en sus 2 principales bases electorales -Canelones $(-6 \%)$ y Montevideo $(-12 \%)$.

\section{Los efectos del sistema electoral. La vigencia de Duverger}


Los efectos de los sistemas electorales (SE) han sido largamente estudiados, desde las ya clásicas "leyes de Duverger"57 (1957) y sus reformulaciones (Rae 1971; Riker 1982 y 1986; Shugart y Carey 1992; Sartori 1994). Los supuestos que adjudican influencia al SE han producido un extenso material y es reconocido que los efectos dependen, en gran medida, de la combinación de sus distintos componentes.

Uno de los puntos de acuerdo en los estudios sobre los efectos de los SE es que la fragmentación de los sistemas de partidos depende de la magnitud de la circunscripción (M), o sea, el número de cargos que se eligen en un distrito electoral. Ceteris paribus, si M se contrae el número de partidos se reduce (Rae 1971; Taagepera y Shugart 1989; Lijphart 1994; Cox 1997).

Como bien señala Lago (2009:10) los "...mecanismos causales detrás de esta generalización empírica fueron originalmente planteados por Duverger (1957) en su seminal estudio sobre partidos políticos: a) un efecto «mecánico» de infrarrepresentación de los partidos perdedores y b) un efecto «psicológico» de los votantes que no desean malgastar su voto respaldando a partidos perdedores. Las condiciones teóricas e institucionales que se deben satisfacer para que el comportamiento estratégico de partidos y votantes reduzca el número de competidores electorales han sido desarrolladas por Cox (1997, 1999). Cox demuestra que la gravedad duvergeniana debe ser entendida como la existencia de un umbral superior a la fragmentación: el número de partidos o candidatos viables en los tres sistemas en que Duverger estaba interesado (la mayoría simple en distritos uninominales, la doble vuelta en distritos uninominales y la RP) es igual a la magnitud de distrito más uno, o "regla $M+1$ ".

De acuerdo a la formulación de Duverger (1957) el sistema de MS, donde se elige un único cargo y gana quien obtiene la mayoría relativa de votos, tiende al bipartidismo ${ }^{58}$. Esta afirmación, con algunas reformulaciones ${ }^{59}$, ha encontrado

57 Duverger formula tres leyes sociológicas determinantes en el sistema electoral con influencia en el sistema de partido: 1) El escrutinio mayoritario a una sola vuelta en distritos uninominales tiende al bipartidismo. 2) La RP tiende a un sistema de partidos múltiples e independientes unos de otros. 3) El escrutinio mayoritario a dos vueltas tiende a un multipartidismo atemperado por alianzas.

58 Sintetizando, el argumento consiste en que los votantes tienen incentivos para no votar a partidos no competitivos y sí hacerlo por aquellos que tienen chance de ganar o compartir el poder político. 
sustento en la evidencia empírica comparada (Rae, 1971; Sartori, 1994; Cox, 1997, entre otros).

En el caso analizado resulta electo Intendente el candidato más votado del partido más votado y dada su preeminencia la competencia se centra en la elección de este cargo. La MS es el factor clave que contribuye al efecto reductor de la competencia. Este efecto se aprecia también en la arena intrapartdidaria, generando que al interior del partido la competencia se reduzca a 2 candidatos. En definitiva era factible presuponer que la disputa por los GD estimularía el surgimiento de escenarios bipartidistas.

\subsection{Fragmentación y congruencia de los sistemas de partidos departamentales}

Analizando el ciclo electoral 1999-2000, Buquet (2000:80) realizó una comparación entre la elección de mayo, definida por mayoría simple, y la primera vuelta de octubre, que exige mayoría absoluta y encontró que "[...] el número efectivo de partidos electorales arrojó guarismos estrictamente menores en las 19 elecciones de mayo comparadas con los resultados del mismo departamento en octubre y el promedio nacional descendió de 3.08 a 2.46 entre las dos instancias".

En las elecciones nacionales de octubre de 2004, el Número Efectivo de Partidos (NEP) promedio de todo el país quedó en 2,5 merced a la caída estrepitosa del PC. Pese al crecimiento que este partido experimentó a nivel nacional en mayo 2005, el promedio fue menor aún, situándose en 2,2. En este último ciclo las elecciones de octubre de 2009 nuevamente arrojan un promedio nacional de NEP superior al registrado en las departamentales de 2010, concretamente el NEP se situó en 2,8 y 2,3 respectivamente.

Tabla 7 NEP en elecciones nacionales 2009 y departamentales 2010

\begin{tabular}{|l|l|l|}
\hline Departamento & $\mathbf{2 0 0 9}$ & $\mathbf{2 0 1 0}$ \\
\hline Montevideo & 2,45 & 2,63 \\
\hline Canelones & 2,59 & 2,23 \\
\hline Maldonado & 3,00 & 2,51 \\
\hline Rocha & 2,89 & 2,24 \\
\hline Treinta y Tres & 2,68 & 2,23 \\
\hline Cerro Largo & 2,64 & 2,28 \\
\hline Rivera & 3,04 & 2,63 \\
\hline
\end{tabular}

59 Por ejemplo, Shugart y Carey (1992) sostienen que la MS propicia la pugna electoral entre dos grandes bloques, en tanto que la mayoría absoluta llevaría a una disputa mas fragmentada. 


\begin{tabular}{|l|l|l|}
\hline Artigas & 2,81 & 2,42 \\
\hline Salto & 2,81 & 2,58 \\
\hline Paysandú & 2,68 & 2,36 \\
\hline Río Negro & 2,99 & 2,64 \\
\hline Soriano & 2,88 & 2,17 \\
\hline Colonia & 2,98 & 2,31 \\
\hline San José & 2,81 & 2,08 \\
\hline Flores & 2,84 & 2,10 \\
\hline Florida & 2,97 & 2,46 \\
\hline Durazno & 2,88 & 2,02 \\
\hline Lavalleja & 2,97 & 2,28 \\
\hline Tacuarembó & 2,77 & 1,80 \\
\hline Total & 2,83 & 2,31 \\
\hline
\end{tabular}

Fuente: Elaboración propia sobre datos de la Corte Electoral y del Banco de Datos de la FCS

Parece posible concluir que la elección del Ejecutivo departamental por MS, y su combinación con el sistema de mayoría automática en la representación del legislativo comunal, provocan un estímulo favorable a la competencia bipartidista.

Para ver la interacción de niveles, nacional y los subnacional, realizamos también una comparación a través del Índice de Congruencia ${ }^{60}$ (IC). Un sistema de partidos será congruente cuando los mismos partidos compiten efectivamente tanto en contiendas nacionales como subnacionales, y además presenta patrones de competencia similares. Por el contrario, un sistema de partidos incongruente será aquel donde no solo existen diferentes combinaciones en el nivel subnacional, sino que la relevancia de los partidos, como variará, mientras algunos serán competitivos en todos los departamentos, otros tendrán relevancia solo en algunos.

La Tabla 7 muestra la congruencia entre el sistema de partidos nacional y los subnacionales. Al igual que los resultados del PSNS, la medida de congruencia muestra una importante e incluso creciente nacionalización del sistema de partidos. Esto parece indicar que las transformaciones del sistema de partidos nacional se encuentran distribuidas en forma bastante homogénea a través del territorio.

\footnotetext{
${ }^{60}$ La medida de congruencia captura, en el primer término de la ecuación, la diferencia promedio en el número efectivo de partidos entre los sistemas nacionales y departamentales, y en el segundo término, la varianza entre los sistemas de partidos subnacionales. La fórmula del IC es: $[1 / \mathrm{N} * \Sigma(\mathrm{si}-\mathrm{n})] 2+1 /(\mathrm{N}-1) * \Sigma([\mathrm{si}-$ promedio(s)]2); donde si es el número efectivo de partidos en cada sistema de partidos subnacionales, $n$ el número efectivo de partidos del sistema de partidos a nivel nacional y $N$ por el número total de unidades subnacionales (Gibson y Suárez Cao, 2010).
} 
Tabla 8 Índice de congruencia (1984-2010)

\begin{tabular}{|l|l|l|l|l|l|l|}
\hline Valores desagregados & $\mathbf{1 9 8 4}$ & $\mathbf{1 9 8 9}$ & $\mathbf{1 9 9 4}$ & $\begin{array}{l}\mathbf{1 9 9 9} \\
\mathbf{2 0 0 0}\end{array}$ & $\begin{array}{l}\mathbf{2 0 0 4} \\
\mathbf{2 0 0 5}\end{array}$ & $\begin{array}{l}\mathbf{2 0 0 9} \\
\mathbf{2 0 1 0}\end{array}$ \\
\hline NEP promedio a nivel nacional & 3 & 3,4 & 3,4 & 3,08 & 2,54 & 2,83 \\
\hline NEP promedio a nivel departamental & 2,4 & 2,5 & 2,8 & 2,49 & 2,24 & 2,31 \\
\hline $\begin{array}{l}\text { Diferencia promedio de los NEP } \\
\text { subnacionales con el NEP nacional }\end{array}$ & 0,30 & 0,69 & 0,33 & 0,35 & 0,09 & 0,26 \\
\hline $\begin{array}{l}\text { Varianza entre Ios NEP } \\
\text { subnacionales } \\
\text { Índice de congruencia }\end{array}$ & $\begin{array}{l}0,032 \\
3\end{array}$ & $\begin{array}{l}0,137 \\
2\end{array}$ & $\begin{array}{l}0,072 \\
0\end{array}$ & $\begin{array}{l}0,232 \\
5\end{array}$ & 0,112 & $\begin{array}{l}0,052 \\
4\end{array}$ \\
\hline
\end{tabular}

Fuente: Elaboración propia sobre datos de la Corte Electoral y del Banco de Datos de la FCS

Las dos alteraciones en el IC las podemos apreciar en las elecciones de 1989 y 1999-2000. En 1989 cabe recordar la fractura del FA y el surgimiento del primer Nuevo Espacio ${ }^{61}$. Además ya mencionamos que si bien existía una hoja para los cargos nacionales y otra hoja para los cargos municipales, no era posible votar por lemas diferentes en las distintas instancias. Esta simultaneidad y vinculación de la elección provocaba un efecto arrastre de la elección nacional sobre la departamental. La única posibilidad que tenía el elector para no verse obligado a sufragar por el mismo lema en ambos niveles era votar en blanco en uno, por un lema en la elección nacional y en blanco en la municipal, o viceversa. En las elecciones de 1989 en Montevideo las hojas municipales del FA tuvieran una diferencia de $2,3 \%$ sobre las nacionales, consecuencia de que votantes blancos y colorados no incluyeron la hoja departamental para favorecer al candidato frentista Tabaré Vázquez, o por electores que sólo incluían la hoja departamental del FA. Lo mismo aconteció en Artigas, si bien en porcentajes menores. Allí el PN obtuvo más votos que el PC en las hojas nacionales (40,9\% frente a 39,5\%), pero ocurrió a la inversa en las hojas departamentales $(40,4 \%$ a $39,3 \%)$ a favor de los colorados, gracias a lo cual Artigas se mantuvo como uno de los dos departamentos gobernados por el PC.

Para el ciclo 1999-2000 influyó decisivamente la separación de las elecciones nacionales de las departamentales, ya que disminuyó el efecto de arrastre de las

${ }^{61}$ Coalición conformada por el Partido por el Gobierno del Pueblo, el Partido Demócrata Cristiano (ambos escindidos del FA) y la Unión Cívica. 
elecciones nacionales. Esto permitió que intendentes populares pudieran ser reelectos sin que la debacle de su partido en el ámbito nacional los arrastrara, a diferencia de lo que le ocurrió al PC en 1989. El FA sólo se mantuvo primero en Montevideo, donde conquistó nuevamente la intendencia, en tanto que pasó del primer al segundo lugar en Canelones, Maldonado y Paysandú.

Tabla 9 Diferencia (\%) entre la votación del FA en el ciclo electoral 19992000

\begin{tabular}{|l|l|l|l|l|l|}
\hline Departamentos & $\mathbf{1 9 9 9}$ & Posición & $\mathbf{2 0 0 0}$ & Posición & Diferencia \\
\hline Montevideo & 52 & $\mathbf{1}$ & 58 & 1 & 6 \\
\hline Canelones & 39 & $\mathbf{1}$ & 40 & 2 & 1 \\
\hline Maldonado & 36 & $\mathbf{1}$ & 35 & 2 & -1 \\
\hline Rocha & 28 & 3 & 16 & 3 & -12 \\
\hline Treinta y Tres & 23 & 3 & 14 & 3 & -9 \\
\hline Cerro Largo & 27 & 3 & 19 & 2 & -8 \\
\hline Rivera & 19 & 3 & 12 & 3 & -8 \\
\hline Artigas & 23 & 3 & 15 & 3 & -7 \\
\hline Salto & 32 & 2 & 21 & 3 & -11 \\
\hline Paysandú & 42 & $\mathbf{1}$ & 37 & 2 & -5 \\
\hline Río Negro & 29 & 2 & 22 & 3 & -7 \\
\hline Soriano & 33 & 2 & 23 & 3 & -10 \\
\hline Colonia & 30 & 3 & 17 & 3 & -13 \\
\hline San José & 31 & 2 & 20 & 2 & -11 \\
\hline Flores & 22 & 3 & 8 & 3 & -14 \\
\hline Florida & 29 & 3 & 22 & 3 & -7 \\
\hline Durazno & 22 & 3 & 12 & 3 & -10 \\
\hline Lavalleja & 3 & 12 & 3 & -9 \\
\hline & 21 & & & & \\
\hline
\end{tabular}




\begin{tabular}{|l|l|l|l|l|l|}
\hline Tacuarembó & 22 & 3 & 14 & 2 & -8 \\
\hline Interior & 31 & 2 & 25 & 3 & -6 \\
\hline TOTAL & 40 & & 39 & & -1 \\
\hline
\end{tabular}

Fuente: Elaboración propia sobre datos de la Corte Electoral y del Banco de Datos de la FCS

Una pregunta que surge es qué sucedió en mayo en aquellos departamentos donde había obtenido un elevado porcentaje de adhesión en octubre. Una respuesta posible es que el electorado de estos distritos se movió con mucha independencia, y así como optó por volcarse al FA en octubre de 1999, no dudó en volver a los lemas tradicionales para decidir en los hechos la competencia local bajo otros parámetros. Para un análisis más detallado ver Cardarello-Guerrini, 2004.

\subsection{La conformación de escenarios 2010}

La recuperación del PC en octubre 2009 había generado cierta sensación de que una buena votación colorada en 2010 favorecía las posibilidades del FA. Esto porque al generarse escenarios tripartitos se acrecentaba la probabilidad del FA de retener los GD de Salto o Florida. Sin embargo, la teoría de la minoría mayor se derrumbó por efecto del efecto de la MS, que se tradujo en un trasvase de votos entre el PN y PC. Era esperable que donde el FA competía contra uno de los PPTT, este recogiera el apoyo del electorado del otro.

Tabla 10 Votos válidos (\%) en las Nacionales 2009 y Departamentales 2010

\begin{tabular}{|l|l|l|l|l|l|l|}
\hline \multirow{2}{*}{ Departamento } & FA & \multicolumn{2}{l|}{ PN } & PC \\
\cline { 2 - 7 } & 2009 & $\mathbf{2 0 1 0}$ & 2009 & $\mathbf{2 0 1 0}$ & 2009 & $\mathbf{2 0 1 0}$ \\
\hline Montevideo & 57.7 & 53.3 & 22.4 & 22.9 & 15.4 & 21.0 \\
\hline Canelones & 52.9 & $\mathbf{6 0 . 6}$ & 29.1 & 26.3 & 14.8 & 11.0 \\
\hline Maldonado & 42.2 & $\mathbf{5 2 . 0}$ & 32.6 & 33.1 & 22.0 & 13.7 \\
\hline
\end{tabular}




\begin{tabular}{|l|l|l|l|l|l|l|}
\hline Rocha & 42.8 & $\mathbf{5 7 . 5}$ & 35.0 & 33.0 & 19.9 & 8.5 \\
\hline Treinta y Tres & 39.1 & $\mathbf{4 2 . 3}$ & 44.4 & $\mathbf{5 1 . 6}$ & 14.8 & 5.5 \\
\hline Cerro Largo & 41.1 & 38.3 & 43.6 & 53.3 & 14.0 & 8.2 \\
\hline Rivera & 34.8 & 22.5 & 36.2 & 26.1 & 27.9 & $\mathbf{5 1 . 1}$ \\
\hline Artigas & 37.8 & $\mathbf{4 7 . 4}$ & 42.0 & 42.2 & 19.2 & 10.0 \\
\hline Salto & 47.5 & 42.2 & 27.7 & 13.0 & 23.1 & $\mathbf{4 3 . 9}$ \\
\hline Paysandú & 47.0 & 44.8 & 36.0 & 46.6 & 14.8 & 8.1 \\
\hline Río Negro & 41.6 & 38.8 & 31.2 & 44.8 & 25.4 & 16.4 \\
\hline Soriano & 45.0 & 34.4 & 31.1 & 58.1 & 22.0 & 6.6 \\
\hline Colonia & 39.4 & 33.2 & 36.5 & 55.7 & 21.4 & 10.9 \\
\hline San José & 44.1 & 34.7 & 36.3 & 59.9 & 17.0 & 4.2 \\
\hline Flores & 31.6 & 25.0 & 45.3 & 63.4 & 21.4 & 10.9 \\
\hline Florida & 39.4 & $\mathbf{4 4 . 1}$ & 37.1 & $\mathbf{4 4 . 7}$ & 20.8 & 10.9 \\
\hline Durazno & 35.7 & 27.8 & 42.7 & 64.3 & 19.2 & 6.8 \\
\hline Lavalleja & 31.6 & $\mathbf{3 4 . 0}$ & 42.8 & 56.1 & 23.0 & 9.1 \\
\hline Tacuarembó & 38.2 & 24.3 & 43.1 & 70.3 & 17.0 & 5.4 \\
\hline Total & 49.3 & 47.2 & 29.9 & 34.4 & 17.5 & 16.7 \\
\hline
\end{tabular}

Fuente: Elaboración propia sobre datos de la Corte Electoral y del Banco de Datos de la FCS.

En el caso de Salto para el FA la recuperación del PC podía suponer una ventaja ya que ese crecimiento sería a expensas del PN, su contendor por el GD en 2005. Pero la recuperación del PC gracias a los votos del electorado nacionalista fue de tal magnitud que le permitió ganar el GD. Algo similar, pero a la inversa, ocurrió en Florida donde votantes colorados terminaron optando por el PN y el PC bajo su votación a prácticamente la mitad.

También se especulaba con que la muy buena votación del FA en la elección nacional 2009 en departamentos como Cerro Largo, Río Negro, San José o Soriano se trasladaría a la elección departamental. De este modo no solo se subestimaba el peso político de dirigentes como Juan Chiruchi ${ }^{62}$ en San José, sino el comportamiento de los dirigentes colorados y su comprensión del sistema electoral. En el referido departamento, el dirigente colorado local Zunino desafió el apercibimiento de la cúpula partidaria y continuó, como lo hizo desde 2000, apoyando el continuismo de Chiruchi votando dentro del lema PN en hojas que lo identificaban como colorado.

62 Electo Intendente en 1984, 1989, 2000 y 2005, ha tenido además la capacidad de nominar un sucesor en forma exitosa cuando no podía ser candidato: Jorge Cerdeña en 1994 y José Luis Falero en 2010. 


\subsection{El sistema de MS y las preferencias del electorado}

En la última etapa de la campaña se produjo enfrentamiento, entre dirigentes del PN y el líder del PC Pedro Bordaberry, en torno a la idea de la necesidad de los PPTT de votar juntos o de crear un lema ad hoc que reuniera a ambos en algunos departamentos. Para Bordaberry y la dirigencia colorada en general no resultaba fácil después de la recuperación obtenida en octubre de 2009 con la operación "retorno a casa" de los electores colorados, pedir el voto para candidatos nacionalistas ${ }^{63}$. La fórmula de MS estimula la competencia entre 2 partidos y si no coordinan los partidos, los que coordinan son los electores. Esta situación ya se había observado en $2000^{64}$. En 2010 electores nacionalistas en Salto votaron al PC, colorados en Florida votaron al PN, incluso en Cerro Largo hubo un mayor traspaso de votos colorados al PN que en otras elecciones porque se preveía que la elección podía ser competitiva con la izquierda.

Esta instancia demostró que no resulta imprescindible la creación de ese "Partido Oriental", como se propuso en alguna editorial ${ }^{65}$ y que postulan algunos integrantes de las colectividades tradicionales, para poder derrotar al FA. Sino que los 2 PPTT pueden coexistir $y$, al mismo tiempo, hacer acuerdos, más o menos explícitos, y otras veces es el mismo elector el que toma cuenta del escenario. La ventaja es la supervivencia de ambos partidos, los electores se inclinan por aquel que presenta la mejor ofertas ${ }^{66}$.

\subsection{Los Intendentes y la reelección}

63 Esta actitud había quedado bastante clara en oportunidad del balotaje, donde la posición del PC fue dar su apoyo a la formula Lacalle-Larrañaga pero en forma poco entusiasta.

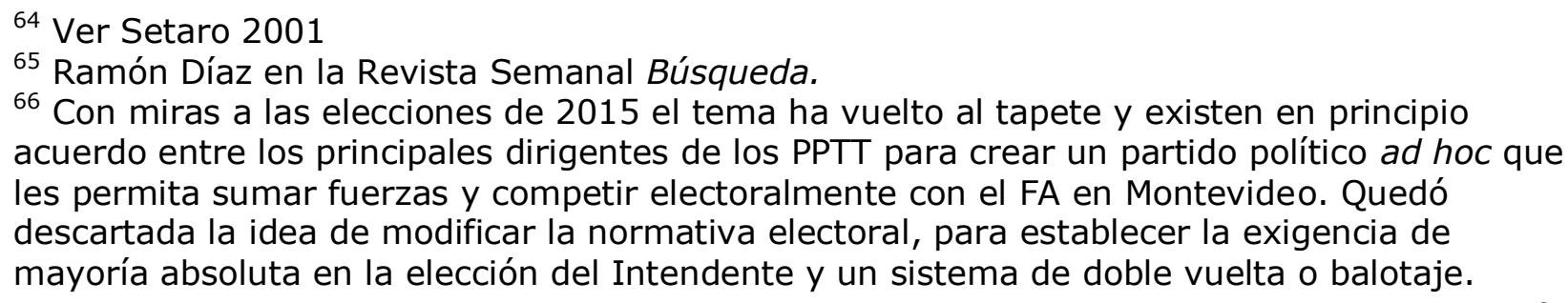
acuerdo entre los principales dirigentes de los PPTT para crear un partido político ad hoc que les permita sumar fuerzas y competir electoralmente con el FA en Montevideo. Quedó descartada la idea de modificar la normativa electoral, para establecer la exigencia de mayoría absoluta en la elección del Intendente y un sistema de doble vuelta o balotaje. 
La RI del ejecutivo es un factor considerable peso en las elecciones departamentales. El FA que había experimentado esta situación una vez ${ }^{67}$, contaba en esta ocasión con 8 intendentes que podían aspirar a la reelección, aunque finalmente este número se redujo a $7^{68}$.

Para el resto se confiaba el resultado en el desempeño de su gestión y la interna partidaria. En el caso del Intendente canario, Carámbula, la interrogante era en qué medida su pre-candidatura presidencial en junio de 2009 podría afectar una reelección que antes de su postulación parecía más que probable, además de cuestionamientos internos a su gestión. En Maldonado, De los Santos tenía como mayor dificultad en la consecución de este objetivo su duro enfrentamiento político con el otro referente del frenteamplismo fernandino y acérrimo rival en la interna, Darío Pérez. Más factible se presentaba el escenario para el Intendente de Rocha, Barrios, quien contaba con una considerable aprobación de su gestión. Los intendentes Pintos (Paysandú), Fonticiella (Salto), Amaral (Treinta y Tres) y Giachetto (Florida), si bien podían considerarse favoritos a priori, enfrentaban un duro desafío por parte de aspirantes de otros partidos.

En las elecciones municipales de 2010, 13 Intendentes procuraron su reelección. Discriminados por partido, el FA presentó 7 aspirantes a reelegirse mientras los restantes 6 pertenecían al PN.

Tabla 11 Candidatos a la Reelección Inmediata ${ }^{69}$

\begin{tabular}{|l|l|l|}
\hline \multirow{2}{*}{ Departamento } & Partido & PN \\
\cline { 2 - 3 } & FA & - \\
\hline Canelones & Marcos Carámbula & - \\
\hline Maldonado & Oscar de los Santos & - \\
\hline Rocha & Artigas Barrios & - \\
\hline Treinta y Tres & Gerardo Amaral & - \\
\hline
\end{tabular}

${ }^{67}$ con la reelección de Arana en Montevideo en las elecciones de 2000

68 En Montevideo la dirigencia nacional y el Presidente Mujica en particular, optaron por no postular al titular del ejecutivo Ricardo Erlich para otro mandato. Perteneciente al mismo sector que el Mujica, el MLN y sus aliados convergentes en el MPP y el Espacio 609, Ehrlich había sido un candidato de consenso de último momento para las elecciones de 2005.

${ }^{69}$ Se destaca en negrita a aquellos que alcanzaron la reelección. 


\begin{tabular}{|l|l|l|}
\hline Artigas & - & Julio Silveira \\
\hline Salto & Ramón Fonticiella & - \\
\hline Paysandú & Julio Pintos & - \\
\hline Río Negro & - & Omar Lafluf \\
\hline Soriano & - & Guillermo Besozzi \\
\hline Colonia & - & Walter Zimmer \\
\hline Flores & - & Armando Castaingdebat \\
\hline Florida & Juan Giachetto & - \\
\hline Tacuarembó & - & Wilson Ezquerra \\
\hline
\end{tabular}

Fuente: Elaboración propia sobre datos de la Corte Electoral y del Banco de Datos de la FCS

Algunos estudios (Jones, 1999) han encontrado una fuerte correspondencia entre la RI y variables que hacen a la competencia y al apoyo del gobierno. Si bien las hipótesis pronosticadas por Jones están previstas para los presidencialismos, son trasladables a nivel subnacional. (Snyder, 2001; Cardarello, 2005 y 2009).

La presencia del titular del cargo que busca la reelección (incumbent) favorece la existencia de competencias electorales bipolares. Por otra parte, cuando quien ocupa el cargo en disputa participa de la competencia, la campaña cobra por lo general un carácter plebiscitario, esto es, una votación a favor o en contra de la gestión del jefe de gobierno que aspira a la reelección.

La presencia del incumbent también genera efectos sobre el número efectivo de candidatos (NEC). Según estudios (Cardarello, 2005 y 2009) la presencia del incumbent tiene un significativo efecto reductor sobre el número efectivo de candidatos.

Otro efecto importante señalado por Jones es como la presencia del titular del cargo que busca la reelección favorece un vigoroso efecto reductor sobre el NEP, lo que redundaría en una menor fragmentación del sistema de partidos. Sin embargo, ese efecto no parece producirse en las elecciones departamentales (Cardarello, 2009) y tampoco las elecciones analizadas aquí como puede apreciarse en el siguiente cuadro. 
Tabla 12 Comparativo NEP en mayo 2010 con y sin incumbent

\begin{tabular}{|c|c|c|c|}
\hline \multicolumn{2}{|l|}{ Con Incumbent } & \multicolumn{2}{|l|}{ Sin Incumbent } \\
\hline Departamento & NEP & Departamento & NEP \\
\hline Canelones & 2,23 & Montevideo & 2,63 \\
\hline Maldonado & 2,51 & Cerro Largo & 2,28 \\
\hline Rocha & 2,24 & Rivera & 2,63 \\
\hline Treinta y Tres & 2,23 & San José & 2,08 \\
\hline Artigas & 2,42 & Durazno & 2,02 \\
\hline Salto & 2,58 & Lavalleja & 2,28 \\
\hline Paysandú & 2,36 & Media & 2,32 \\
\hline Río Negro & 2,64 & & \\
\hline Soriano & 2,17 & & \\
\hline Colonia & 2,31 & & \\
\hline Flores & 2,10 & & \\
\hline Florida & 2,46 & & \\
\hline Tacuarembó & 1,80 & & \\
\hline Media & 2,31 & & \\
\hline
\end{tabular}

Fuente: Elaboración propia sobre datos de la Corte Electoral y del Banco de Datos de la FCS

El total de incumbents exitosos del período (1984-2010) se sitúa en 50,8\% o sea que poco más de la mitad de los candidatos que aspiran a la reelección la consigue. Pero podían marcarse diferencias cuando las elecciones eran vinculadas y simultáneas con las nacionales la tasa de reelección se ubicó en el $40 \%$ en 1989, y en el $30 \%$ en 1994. 
Tabla 13 Tasa de reelección (1989-2010)

\begin{tabular}{|l|l|l|l|l|l|l|}
\hline Candidatos & $\mathbf{1 9 8 4 - 8 9}$ & $\mathbf{1 9 8 9 - 9 4}$ & $\mathbf{1 9 9 4 - 2 0 0 0}$ & $\mathbf{2 0 0 0 - 0 5}$ & $\mathbf{2 0 0 5 - 1 0}$ & Total \\
\hline Incumbents & 15 & 10 & 13 & 10 & 13 & 61 \\
\hline Reelectos & 6 & 3 & 9 & 5 & 8 & 31 \\
\hline Tasa reelección & 40 & 30 & 69.2 & 50 & 61.5 & 50.8 \\
\hline
\end{tabular}

Fuente: Elaboración propia sobre datos de la Corte Electoral y del Banco de Datos de la FCS

La situación ha variado luego de la separación de las nacionales de las departamentales: y en 2000 la tasa se situó en $69.2 \%$, la más alta del período, mientras que en 2005 se ubicó en $50 \%$ y en 2010 lo hizo en el $61.5 \%$.

Tabla 14 Porcentaje de éxito de incumbents por partido (1989-2010)

\begin{tabular}{|l|l|l|l|}
\hline Elección & PC & PN & FA \\
\hline $\mathbf{1 9 8 9}$ & 11 & 83 & - \\
\hline $\mathbf{1 9 9 4}$ & 0 & 33 & - \\
\hline $\mathbf{2 0 0 0}$ & 60 & 71 & 100 \\
\hline $\mathbf{2 0 0 5}$ & 50 & 50 & - \\
\hline $\mathbf{2 0 1 0}$ & - & 83,3 & 42,9 \\
\hline Total & 29 & 61 & 50 \\
\hline
\end{tabular}

Fuente: Elaboración propia sobre datos de la Corte Electoral y del Banco de Datos de la FCS 
En esta elección 5 de 6 Intendentes nacionalistas alcanzaron la reelección lo que hizo que su tasa fuera la más alta $(83,3 \%)$ frente a 3 de 7 intendentes frenteamplistas que lo lograron, con una tasa de reelección de 42,9\%.

A lo largo del período considerado desde 1989 los Intendentes blancos son también los más reelectos: 22 de $36(61,1 \%)$. Entre los frenteamplistas 4 de 8 han sido reelectos $(50 \%)$, mientras que menos de un tercio de los colorados lo consiguió 5 de $17(29,4 \%)$. Por lo que el PN se convierte en el partido más exitoso en lo que al éxito de sus incumbents se refiere a lo largo del todo el período. Por un lado PN es el partido con más intendentes, pero además es el que más candidatos ha presentado y el que gobierna departamentos en los que es un partido predominante (Magri, 2000).

En definitiva lo que se observa tener un incumbent no asegura la victoria, 4 de los 7 incumbents del FA fueron derrotados, si bien como mencionamos en 2 caso el incumbent recibió más votos que al ser electo. Esto deja entrever que en departamentos de gran competitividad el sistema de MS operó contra el FA.

\section{El aumento de los votos en blanco y anulado}

En estas elecciones el porcentaje de voto en blanco o anulado, que registraba una media histórica del 3\% fuera para comicios nacionales o departamentales fue superado. Esto que puede verse como una expresión explícita de abstencionismo por parte del electorado requiere ciertos matices $^{70}$.

Lo cierto es que en 2010, sin tomar a los votos en blanco parciales, el promedio alcanzó el $7.7 \%$, siendo los casos más altos el $11.7 \%$ en Montevideo y el $8.7 \%$ en Canelones. Los más aproximados a la tendencia histórica fueron Treinta y Tres (2.9\%), Cerro Largo (2.5) y Artigas (3.1\%); el resto la sobrepasó ampliamente en rangos entre el $3.5 \%$ y el $5.6 \%$. Cuando la diferencia está en uno o dos casos, las razones pueden ser particulares, pero cuando el $84 \%$ del universo sufre cambios, es plausible pensar en razones generales que provocaron el desvío de la

\footnotetext{
${ }^{70}$ Strictu sensu la abstención implica que elector no hace uso de su derecho al sufragio, mientras que el voto en blanco es un voto de protesta, lo que Bottinelli llama "voto refractario". En este caso el elector no renuncia a su derecho y concurre a votar, sobre allí donde el voto es obligatorio, pero marca su descontento con algún aspecto de las elecciones - la oferta, los partidos o el sistema político. Un ejemplo ilustrativo en este sentido son las recordadas las elecciones legislativas de Argentina en octubre de 2001 donde el voto en blanco denominado "voto bronca" y bajo la consigna "que se vayan todos" se transformó en la segunda opción más votada detrás del PJ. Lo mismo ocurre con el voto anulado, aunque no es tan claro, ya que en ocasiones puede tratarse simplemente un error en el acto de sufragar.
} 
tendencia que necesitan de una investigación más profunda. Los resultados de mayo 2010 arrojan los siguientes guarismos:

Tabla 15 Voto en blanco y anulado por departamento (\%)

\begin{tabular}{|l|l|l|l|l|l|}
\hline Departamento & En Blanco & Anulados & EB + A & Blanco parcial & Total \\
\hline Montevideo & 7,6 & 4,1 & $\mathbf{1 1 , 7}$ & 2,1 & 13,8 \\
\hline Canelones & 5,8 & 2,9 & $\mathbf{8 , 7}$ & 4,7 & 13,4 \\
\hline Maldonado & 2,9 & 1,8 & $\mathbf{4 , 7}$ & 3,0 & 7,8 \\
\hline Rocha & 3,9 & 1,7 & $\mathbf{5 , 6}$ & 3,1 & 8,7 \\
\hline Treinta y Tres & 1,8 & 1,1 & $\mathbf{2 , 9}$ & 0,8 & 3,7 \\
\hline Cerro Largo & 1,7 & 0,8 & $\mathbf{2 , 5}$ & 5,0 & 7,6 \\
\hline Rivera & 2,7 & 1,1 & $\mathbf{3 , 8}$ & 1,4 & 5,2 \\
\hline Artigas & 2 & 1,1 & $\mathbf{3 , 1}$ & 2,5 & 5,6 \\
\hline Salto & 2,5 & 1 & $\mathbf{3 , 5}$ & 0,9 & 4,4 \\
\hline Paysandú & 2,7 & 1,5 & $\mathbf{4 , 2}$ & 1,4 & 5,6 \\
\hline Río Negro & 2,5 & 1,4 & $\mathbf{3 , 9}$ & 1,5 & 5,3 \\
\hline Soriano & 3 & 1,4 & $\mathbf{4 , 4}$ & 2,9 & 7,3 \\
\hline Colonia & 2,8 & 1,7 & $\mathbf{4 , 5}$ & 3,6 & 8,0 \\
\hline San José & 3,3 & 1,5 & $\mathbf{4 , 8}$ & 1,9 & 6,7 \\
\hline Flores & 3,6 & 1,5 & $\mathbf{5 , 1}$ & 0,8 & 6,0 \\
\hline Florida & 2,8 & 1,4 & $\mathbf{4 , 2}$ & 1,2 & 5,4 \\
\hline Durazno & 2,8 & 1,2 & $\mathbf{4}$ & 1,0 & 5,7 \\
\hline Lavalleja & 3,1 & 1,3 & $\mathbf{4 , 4}$ & 1,3 & $\mathbf{3}$ \\
\hline Tacuarembó & 2,2 & 1,3 & $\mathbf{3 , 5}$ & 1,4 & \\
\hline
\end{tabular}




\begin{tabular}{|l|l|l|l|l|l|}
\hline Total & 5,1 & 2,6 & $\mathbf{7 , 7}$ & 2,5 & 10,2 \\
\hline
\end{tabular}

Fuente: Elaboración propia sobre datos de la Corte Electoral y del Banco de Datos de la FCS

Un factor puede consistir en el desgaste electoral luego de un extenso periplo de casi un año, sin embargo en comparación con la instancia anterior, no estaría actuando como un factor explicativo sólido. No obstante es verdad que en 2004 el desgaste fue menor en tanto no hubo balotaje. Otra explicación podría ir en el sentido de que el comportamiento del electorado no necesariamente fue acompasándose automáticamente a las modificaciones que se producen en el sistema electoral. Una hipótesis en este sentido podría ser que al electorado le lleva un par de ciclos ajustarse a la nueva modalidad del sistema y recién en la tercera experiencia expresa su rechazo a la misma.

Tabla 16 Voto en Blanco y Anulado (\%) por departamento en 2000-10

\begin{tabular}{|l|l|l|l|}
\hline Departamento & $\mathbf{2 0 0 0}$ & $\mathbf{2 0 0 5}$ & $\mathbf{2 0 1 0}$ \\
\hline Montevideo & 3,2 & 3,9 & 11,7 \\
\hline Canelones & 3,7 & 5,2 & 8,7 \\
\hline Maldonado & 2,8 & 2,8 & 4,7 \\
\hline Rocha & 3,3 & 4,6 & 5,6 \\
\hline Treinta y Tres & 2,7 & 2,9 & 2,9 \\
\hline Cerro Largo & 2,4 & 2,3 & 2,5 \\
\hline Rivera & 3,1 & 2,9 & 3,8 \\
\hline Artigas & 2,3 & 2,5 & 3,1 \\
\hline Salto & 2,8 & 2,8 & 3,5 \\
\hline Paysandú & 2,4 & 2,5 & 4,2 \\
\hline Río Negro & 3,6 & 3,0 & 3,9 \\
\hline Soriano & 2,7 & 3,5 & 4,4 \\
\hline Colonia & 3,8 & 3,7 & 4,5 \\
\hline
\end{tabular}




\begin{tabular}{|l|l|l|l|}
\hline San José & 2,6 & 3,4 & 4,8 \\
\hline Flores & 2,1 & 2,3 & 5,1 \\
\hline Florida & 2,7 & 3,3 & 4,2 \\
\hline Durazno & 3,4 & 3,2 & 4 \\
\hline Lavalleja & 3,7 & 3,3 & 4,4 \\
\hline Tacuarembó & 2,1 & 2,5 & 3,5 \\
\hline Total & 3,1 & 3,7 & 7,7 \\
\hline
\end{tabular}

Fuente: Elaboración propia sobre datos de la Corte Electoral y del Banco de Datos de la FCS

Otro factor puede haber resultado de la introducción de las elecciones municipales $^{71}$ que se votan en forma vinculada y simultánea con al elección departamental. Esto, combinado con la exigua difusión que se le otorgó a la elección de tercer nivel debido al escaso tiempo entre la aprobación y su implementación, puede haber generado cierta resistencia entre el electorado porque debía armonizar sus preferencias departamentales con las municipales, siendo la única alternativa el votar en blanco en alguno de los niveles. ${ }^{72}$

Un tercer factor atañe a los partidos, que puede apreciarse al desagregar la votación por departamento. En los departamentos conquistados por PN y PC, el voto en blanco (total) y anulado, se ubicó entre el $2.5 \%$ al $5.1 \%$. En los departamentos donde triunfó el PN se registro un mayor nivel en el voto en blanco y anulado (4\% de promedio) que en los ganados por el PC (3.65\% promedio).

71 Entre 2009 y 2010 el Parlamento uruguayo aprobó la Ley de Descentralización Política y Participación Ciudadana que habilitó la creación del tercer nivel de gobierno. Las elecciones se realizan en forma simultánea con las departamentales. Si bien sus autoridades se eligen en una Hoja de Votación separada no está permitido votar por un partido a nivel departamental y por otro en el municipal ("voto cruzado"), so pena de anular el voto. Los municipios estarán integrados por cinco miembros y sus cargos serán electivos y distribuidos por el sistema de representación proporcional. La titularidad del ejecutivo será ejercido por el primer titular de la lista más votada del lema más votado en cada municipio y se denominará alcalde. Los restantes cuatro miembros se denominarán concejales y serán de carácter honorario. En esta primera instancia se eligieron 89 alcaldías en todo el país.

72 En este mismo libro artículo "Municipales 2010: elecciones de segundo orden" Magri, A y M Freigedo. 
En aquellos donde se conforman escenarios conflictivos podría resultar afectada la confianza y adhesión del votante al partido. Una explicación de las cifras tan altas que el voto en blanco registra en dos departamentos frenteamplistas como Montevideo y Canelones, puede estar relacionada con la disconformidad del votante hacia la estructura organizacional y los procedimientos de selección de candidaturas.

En Montevideo, puede suponerse que un porcentaje significativo del voto en blanco corresponde a los frenteamplistas, dado que los otros partidos en relación a anteriores elecciones compensan las diferencias. Si nos apoyamos en la hipótesis de votantes "tradicionales" que fluctúan entre el PN y el PC, un $50 \%$ de lo que aumenta el PN en 2010 corresponde a lo que pierde el PC respecto a 2005.

Los 8 puntos que pierde el FA se puede conjeturar que corresponden a votantes izquierda descontentos o bien con la gestión de la última administración o bien con el proceso de selección del candidato o lo que es más probable un poco de ambas, sin descontar tampoco un efecto de desgaste tras 20 años al frente de la comuna.

Tabla 17 Votación válida por partido en Montevideo, 2000-2010 (\%)

\begin{tabular}{|l|l|l|l|l|}
\hline Partido/elección & $\mathbf{2 0 0 0}$ & $\mathbf{2 0 0 5}$ & $\mathbf{2 0 1 0}$ & Dif. 2005-10 \\
\hline FA & 58.3 & 60.9 & 53.2 & -7.7 \\
\hline PN & 11.7 & 10.4 & 22.9 & +12.9 \\
\hline PC & 28.1 & 26.9 & 20.9 & -5.9 \\
\hline
\end{tabular}

Fuente: Elaboración propia sobre datos de la Corte Electoral y del Banco de Datos de la FCS

En Montevideo los procedimientos para seleccionar al candidato del FA, se ajustaron a la forma en que la izquierda lo hecho tradicionalmente, es decir es el congreso del FA quien decide no solo el nombre, sino en el caso de la departamentales, si se permite el uso del DVS en algunos casos.

En esta oportunidad quizá se dejo traslucir demasiado los acuerdos entre sectores del FA que determinaron la candidatura única y la elección del candidato ${ }^{73}$.

73 Se percibió por parte del electorado frenteamplista que la designación del candidato correspondía a arreglos entre cúpulas y de pagos de favores políticos anteponiéndola a la idoneidad del aspirante. Esta intuición por parte del electorado fue reforzada con declaraciones por parte de algunos dirigentes denunciando un acuerdo gestado en diciembre de 2008 entre el E609 y el PCU. La idea que se difundió fue que a cambio del apoyo del segundo a Mujica en junio, la Intendencia de Montevideo le correspondería al PCU. También 
Más allá de si esto fue así o no, la idea pudo haber provocado el rechazo de parte del electorado del FA a esa práctica. Respecto a la candidatura única, es cierto que la misma es prácticamente una tradición del FA en Montevideo, modalidad que no fue cuestionada per se, sino por la forma en que se procesó.

Creemos por tanto que es una señal reveladora e inequívoca de descontento por parte de la ciudadanía y un mensaje al sistema político que todos los partidos políticos deberían atender.

Lo cierto es que el aumento de voto en blanco tampoco explica la pérdida de $\mathrm{GD}$, porque este crecimiento se registra fundamentalmente en los departamentos donde volvió a ganar el FA.

\section{A modo de conclusiones}

La primera lección que el FA podría extraer es que los ciclos electorales raramente se repiten, 2004-2005 no se repitió 2009-10. En este último fue apreciable una separación entre la elección nacional y la elección departamental. En el proceso anterior claramente hubo un efecto de arrastre de la elección nacional sobre la elección departamental que le permitió al FA incluso ganar varias Intendencias, pese a que incidieron otros factores como la reñida interna nacionalista en Treinta y Tres.

En esta elección acaeció un mayor alejamiento, similar a lo que pasó en el ciclo 1999-2000, y ahí los PPTT aprovecharon, entre otras cosas, los estímulos que genera el sistema electoral para la elección del Intendente.

Para los partidos políticos queda claro que las elecciones de segundo nivel siguen cobrando relevancia para la carrera política de los actores, para recuperarse en el caso del PN y PC. Y en el caso del FA una constancia de que, pese a competir con posibilidades ciertas en la mayoría de los departamentos, el leve retroceso experimentado en 2009 se mantuvo y que gobiernos departamentales obtenidos en 2005 se podían perder y no iba a repetirse automáticamente la experiencia de Montevideo. Lo cual habla de que el electorado premia o castiga de acuerdo a la competencia, la evaluación de gestiones y la oferta electoral de los partidos.

se divulgó la idea de que era una maniobra destinada a perjudicar dos candidatos que pujaban por la candidatura, Daniel Martínez (PS) y Carlos Varela (2121). 
Lo cierto es que para entender este proceso electoral y explicar el retroceso del FA en lo que a GD refiere, el factor fundamental es el sistema electoral y en particular el sistema de MS.

\section{Bibliografía}

Bottinelli, Oscar (1991). El Sistema Electoral Uruguayo. Descripción y Análisis. Working Paper No 3, Instituto de Ciencia Política, Heildelberg

Buquet, Daniel (2005). "Elecciones uruguayas 2004-2005: de la vieja oposición a la nueva mayoría", en Buquet, Daniel (coord.) Las claves del cambio. Ciclo electoral y nuevo gobierno 2004/2005. Montevideo. Ediciones de la Banda Oriental - Instituto de Ciencia Política.

Buquet, Daniel (2000). "Los Cambios que Aseguraron la Continuidad", en Elecciones 19992000, Instituto de Ciencia Política - Ediciones de la Banda Oriental Montevideo.

Cardarello, Antonio (2011). La búsqueda de saberse inmortal. La reelección inmediata de los ejecutivos subnacionales. Departamento de Ciencia Política, Facultad de Ciencias Sociales, Comisión Sectorial de Investigación Científica (CSIC), Universidad de la República, Montevideo.

Cardarello, Antonio (2009). La reelección inmediata en el ejecutivo a nivel subnacional. Un estudio de tres casos. Tesis de Doctorado en Ciencia Política, Universidade Federal do Rio Grande do Sul, Instituto de Filosofía y Ciencias Humanas, Porto Alegre.

Cardarello, Antonio (2005). "Los Intendentes y la reelección inmediata. Probables efectos y efectos apreciados en 2005.", en Daniel Buquet (coord.): Las Claves del Cambio: ciclo electoral y nuevo gobierno. Págs.149-162. Ediciones de la Banda Oriental Instituto de Ciencia Política de la Facultad de Ciencias Sociales. Universidad de la República, Montevideo. 
Cardarello, Antonio y Aldo Guerrini (2004). "El Frente Amplio en el Interior: La conquista de la legitimidad política", en Jorge Lanzaro (coord.) La izquierda uruguaya entre la oposición y el gobierno. Págs. 321-351 Editorial Fin de Siglo - Instituto de Ciencia Política de la Facultad de Ciencias Sociales. Universidad de la República, Montevideo.

Cox, Gary. (1997). Making Votes Count: Strategic Coordination in the World's Electoral Systems. Cambridge, UK. Cambridge University Press.

Duverger, Maurice. (1954). Los partidos políticos. México, Fundación Cultura Económica.

Gibson, Edward y Julieta Suárez Cao (2010). "Federalized Party Systems and Subnational Party Competition: Theory and an Empirical Application to Argentina", en Comparative Politics, Vol. 43, No 1.

Johnson, Niki (2005). La política de la ausencia: las elecciones uruguayas 2004-200, las mujeres y la equidad de género. Montevideo: CNS Mujeres/ICP.

Jones, M. y Mainwaring, S. (2003). "The Nationalization of Parties and Party Systems", en Party Politics, Vol. 9 No 2 pp. 139-166.

Jones, Mark P. (1999). "Electoral Laws and the Effective Number of Candidates in Presidential Elections", en The Journal of Politics, Vol. 61, No 1, University of Texas Press.

Laakso, Marku y Rein Taagepera (1979). 'Effective Number of Parties: A Measure with Application to West Europe', en Comparative Political Studies 12: 3-27

Lago, Ignacio (2009). "Magnitud de distrito y número de partidos". Revista Española de Ciencia Política 21: 9-23. 
Laurnaga, María Elena (2001). "La geografía de un cambio. Política y elecciones municipales", en María Elena Laurnaga (coord.) La geografía de un cambio. Política, gobierno y gestión municipal en Uruguay, Págs. 11-36, Colección Política Viva, Ediciones de la Banda Oriental - Instituto de Ciencia Política de la Facultad de Ciencias Sociales. Universidad de la República, Montevideo.

Lijphart, Arend (1994). Electoral Systems and Party Systems: A Study of Twenty-Seven Democracies. Oxford: Oxford University Press.

López, Santiago (2007). "¿Son las elecciones municipales elecciones locales? Estimando diferencias de resultados y comportamiento electoral", en Revista Uruguaya de Ciencia Política No 16. pp. 73-102. Ediciones Cauce - Instituto de Ciencia Política, Montevideo.

Magri, Altair (2000). "La llave del triunfo electoral en Mayo 2000: reelección, continuidad y por la vuelta", en Elecciones 1999-2000 Instituto de Ciencia Política Ediciones de la Banda Oriental..Montevideo.

Moraes, Juan A., (1997). "Mayoría Automática en el Uruguay: La Experiencia de los Gobiernos Departamentales", en Revista Uruguaya de Ciencia Política, No10. Fundación de Cultura Universitaria - Instituto de Ciencia Política, Montevideo.

Pérez, Verónica (2005). "Algunos cambios, pero no tantos: La presencia femenina en cargos ejecutivos en Uruguay", en Daniel Buquet (coord.): Las Claves del Cambio: ciclo electoral y nuevo gobierno. Págs. 205-224. Ediciones de la Banda Oriental Instituto de Ciencia Política de la Facultad de Ciencias Sociales. Universidad de la República, Montevideo.

Rae, Douglas W. (1971). The Political Consequences of Electoral Laws. New Haven, CT. Yale University Press.

Riker, William H. (1986). "Duverger's Law Revisited". En Bernard Grofman and Arend Lijphart (eds.) Electoral Laws and heir Political Consequences. New York: Agathon Press, pp. 19-42. 
Riker, William H (1982). "he Two-Party System and Duverger's Law: an Essay on the History of Political Science". American Political Science Review 76(4): 753-66.

Sartori, Giovanni (1994). Ingeniería institucional comparada: una investigación de estructuras, incentivos y resultados. México, Fundación Cultura Económica.

Schattschneider, E.E. (1960). The Semi-Sovereign People: A Realist's View of Democracy in America. New York: Holt, Rinehart, and Winston

Shugart, Matthew S. y John M. Carey (1992). Presidents and Assemblies. Constitutional design and electoral dynamics. Cambridge University Press.

Setaro, Marcelo (2001). "La lógica institucional mayoritaria en un escenario competitivo. ¿Una definición por balotaje en Canelones?", en: Ma Elena Laurnaga (coord.) La geografía de un cambio: Política, Gobierno y Gestión Municipal en Uruguay. Ediciones Banda Oriental, Instituto de Ciencia Política. Montevideo.

Snyder, Richard (2001). "Scaling Down: The Subnational Comparative Method" en Studies in Comparative International Development, Spring 2001, Vol. 36, No. 1, pp. 93-110.

Sundquist, James L. (1973). Dynamics of the Party System: Alignment and Realignment of Political Parties in the United States. Washington, DC: The Brookings Institution

Taagepera, Rein y Matthew Shugart (1989). Seats and votes: the efects and determinants of electoral systems. New Haven: Yale University Press.

Traversa, Federico (2001). "Elecciones municipales de mayo del 2000: una perspectiva de análisis para interpretar los resultados y el caso particular del departamento de 
Colonia", en: Ma Elena Laurnaga (coord.) La geografía de un cambio: Política, Gobierno y Gestión Municipal en Uruguay. Ediciones Banda Oriental, Instituto de Ciencia Política. Montevideo.

Vairo, Daniela. (2008). "Juntos pero no casados: Los efectos de la reforma constitucional al interior de los partidos", en Revista Uruguaya de Ciencia Política No 17. pp. 159182. Ediciones Cauce - Instituto de Ciencia Política, Montevideo.

\section{Prensa, Internet}

Bottinelli, Oscar A (2010). "9 de mayo: se desató una tempestad cuando se pronosticaba calma". En radio El Espectador, programa En Perspectiva, espacio Análisis político, 14.05.2010.

\section{¿Protesta o cambio institucional?}

Determinantes del voto nulo y blanco en las elecciones departamentales de 2010 en Uruguay en perspectiva comparada

Gerardo Isaac Cisneros Yescas

Martín Freigedo Peláez

\section{Resumen}

Las elecciones departamentales de 2010 en Uruguay arrojaron resultados anómalos para los estándares del país, los cuales están asociadas a un significativo aumento 